\title{
Anticancer Properties of Graviola (Annona muricata): A Comprehensive Mechanistic Review
}

\author{
Islam Rady, ${ }^{1}$ Melissa B. Bloch, ${ }^{2}$ Roxane-Cherille N. Chamcheu, ${ }^{1,3}$ Sergette Banang Mbeumi, ${ }^{4}$ \\ Md Rafi Anwar, ${ }^{2}$ Hadir Mohamed, ${ }^{5}$ Abiola S. Babatunde, ${ }^{6}$ Jules-Roger Kuiate, ${ }^{7,8}$ \\ Felicite K. Noubissi, ${ }^{4,9}$ Khalid A. El Sayed, ${ }^{2}$ G. Kerr Whitfield, ${ }^{10}$ \\ and Jean Christopher Chamcheu $\mathbb{D}^{1,2}$
}

\author{
${ }^{1}$ Department of Dermatology, School of Medicine and Public Health, University of Wisconsin-Madison, WI 53706, USA \\ ${ }^{2}$ School of Pharmaceutical and Toxicological Sciences, College of Pharmacy, University of Louisiana at Monroe, Monroe, \\ LA 71201, USA \\ ${ }^{3}$ Madison West High School, 30 Ash St, Madison, WI 53726, USA \\ ${ }^{4}$ Division for Research and Innovation, POHOFI Inc., P.O. Box 44067, Madison, WI 53744, USA \\ ${ }^{5}$ Department of Biochemistry, Faculty of Science, University of Mansoura, Mansoura, Egypt \\ ${ }^{6}$ Department of Hematology, University of Ilorin, Ilorin, Nigeria \\ ${ }^{7}$ Department of Biochemistry, Faculty of Sciences, University of Dschang, Dschang, Cameroon \\ ${ }^{8}$ Section for Research and Innovation, POHOFCAM, P.O. Box 175, Kumba, Cameroon \\ ${ }^{9}$ Department of Biology/RCMI, Jackson State University, 1400 J R Lynch, 429 JAP, Jackson, MS 39217, USA \\ ${ }^{10}$ Department of Basic Medical Sciences, University of Arizona College of Medicine-Phoenix, Phoenix, AZ 85004, USA
}

Correspondence should be addressed to Jean Christopher Chamcheu; chamcheu@ulm.edu

Received 15 February 2018; Accepted 3 June 2018; Published 30 July 2018

Academic Editor: Italo Tempera

Copyright (c) 2018 Islam Rady et al. This is an open access article distributed under the Creative Commons Attribution License, which permits unrestricted use, distribution, and reproduction in any medium, provided the original work is properly cited.

Graviola (Annona muricata) is a small deciduous tropical evergreen fruit tree, belonging to the Annonaceae family, and is widely grown and distributed in tropical and subtropical regions around the world. The aerial parts of graviola have several functions: the fruits have been widely used as food confectionaries, while several preparations, especially decoctions of the bark, fruits, leaves, pericarp, seeds, and roots, have been extensively used in traditional medicine to treat multiple ailments including cancers by local communities in tropical Africa and South America. The reported therapeutic benefits of graviola against various human tumors and disease agents in in vitro culture and preclinical animal model systems are typically tested for their ability to specifically target the disease, while exerting little or no effect on normal cell viability. Over 212 phytochemical ingredients have been reported in graviola extracts prepared from different plant parts. The specific bioactive constituents responsible for the major anticancer, antioxidant, anti-inflammatory, antimicrobial, and other health benefits of graviola include different classes of annonaceous acetogenins (metabolites and products of the polyketide pathway), alkaloids, flavonoids, sterols, and others. This review summarizes the current understanding of the anticancer effects of A. muricata and its constituents on diverse cancer types and disease states, as well as efficacy and safety concerns. It also includes discussion of our current understanding of possible mechanisms of action, with the hope of further stimulating the development of improved and affordable therapies for a variety of ailments.

\section{Introduction}

Cancer is the second leading cause of mortality worldwide. Over 10 million new patients are diagnosed with cancer annually with over 6 million associated deaths, representing roughly $12 \%$ of worldwide mortality [1]. The occurrence of new cancer cases is expected to grow by about $70 \%$ over the next two decades and estimated to reach over 15 million 
new cases diagnosed annually by the year 2020 [2]. This rapid increase is due to both an aging and growing population, along with carcinogens, infections, genetic mutations, hormones, immune conditions, and the adoption of behavioral and dietary risk factors, such as smoking, unhealthy diet, physical inactivity, and environmental pollutants [3]. The risk factors may act singly or in concert to cause mutation of normal cells [4]. Many of these mutations alter the expression or activity of key gene products, causing unregulated cell division leading to cancer. Currently, the main cancer treatment modalities are surgery, radiation-based therapy, chemotherapy, gene therapy, and/or hormonal therapy, either singly or in combination [1]. The most commonly used chemotherapy drugs are antimetabolites, DNA-interacting agents, antitubulin agents, hormones, and molecular targeting agents, all of which work to destroy cancerous cells or limit their proliferation [5]. However, most cytotoxic drugs act on both cancerous and healthy cells and therefore elicit side effects such as hair loss, bone marrow suppression, drug resistance, gastrointestinal lesions, neurologic dysfunction, and cardiac toxicity [5]. Consequently, development of new anticancer agents with higher efficacy, selectivity, and little or no side effects is an urgent goal.

Natural products, especially phytochemicals, have been used to help mankind sustain health since the dawn of medicine [4]. Phytotherapy (also called herbalism or herbal medicine) has provided remedies for ailments, including cancer, to the present day [6]. Dietary phytochemicals have many built-in advantages over synthetic compounds due to their proven safety, low cost, and oral bioavailability [7]. However, it is only recently that researchers have begun to elucidate the mode of action of plant-derived agents at the molecular, cellular, and tissue level [8-10]. Many natural products have now been extensively researched, and numerous compounds have exhibited anticancer and other beneficial actions in modern controlled studies. Most anticancerous natural products interfere with the initiation, development, and progression of cancer by modulating various mechanisms including cellular proliferation, differentiation, apoptosis, angiogenesis, and metastasis [11].

Extracts from Annona muricata (also known as graviola) are among a myriad of botanical products which have shown promising medicinal value [12-14]. Studies have linked $A$. muricata-derived compounds (Table 1 and Figure 1) to a variety of anticancer effects including cytotoxicity [15-18], induction of apoptosis [19-27], necrosis [28], and inhibition of proliferation $[25,29-31]$ on a variety of cancer cell lines, including breast [32], prostate [29], colorectal [25], lung [16], leukemia [33], renal [34], pancreatic [15], hepatic [24], oral [35], melanoma [36], cervical [37], and ovarian cancers [38]. Moreover, all aerial parts of this plant, including the bark, fruit, leaves, root, and seeds, are used as natural medicines in the tropics [39]. However, there is a need for more rigorous studies to establish safe and effective care regimes. This review summarizes the recent advances in the application and mechanisms of A. muricata extracts against several cancers both in vitro and in vivo.

\section{Botanical Description and Distribution}

Annona muricata is a lowland tropical, fruit-bearing tree of the family Annonaceae found in the rainforests of Africa, South America, and Southeast Asia. A. muricata, commonly known as soursop, graviola, guanabana, or Brazilian pawpaw, has large, glossy, dark green leaves $[4,40]$, with edible, green heart-shaped fruits $[4,41]$. Soft, curved spines cover the leathery skin of the fruits, each of which may contain 55-170 black seeds distributed in a creamy white flesh with a characteristic aroma and flavor $[41,42]$. All portions (leaves [16, 18, 31, 38, 43, 44], pericarp [24, 45, 46], fruits $[4,30,47]$, seeds [47-50], and roots [27]) of A. muricata have been used in traditional medicine, but the most widely used in the preparations of traditional medical decoctions are stem barks, roots, seeds, and leaves [51, 52]. Coria-Téllez et al. have reported 212 bioactive compounds in A. muricata extracts [41]. Reports in the literature indicate that seventy-four of these bioactive compounds exhibit a variety of anticancer effects in preclinical cell culture and animal model systems. Several dozen annonaceous acetogenins have been studied ( 59 of which are listed alphabetically in Table 2, with key structural features summarized in Figure 2). Moreover, at least ten solvent extracts (Table 1) in addition to an extract from fungi (Periconia sp.) collected on A. muricata that contains bioactive compounds (Figure 1) have been tested for their anticancer properties and other health benefits.

A. muricata-derived preparations have been utilized to treat numerous ailments, making this plant an ethnomedically important species. In developing tropical countries including Africa, different parts of $A$. muricata are being used to treat conditions such as diabetes $[53,54]$, coughs, skin diseases [55], and cancers [25-27, 56-58]. Furthermore, in both Jamaica [59] and Trinidad [60], A. muricata is the most prevalently used herbal remedy in the treatment of most cancers. For example, in Jamaica, a large proportion of cancer patients use medicinal plants in self-medicating practices, with $A$. muricata being commonly used (along with Petiveria alliacea) for treating breast and prostate cancers, respectively [59].

A. muricata has also been used, mainly in developing tropical countries, for the treatment of arthritis [61], hypertension [62], snake bite [63], diarrhea [59], headache [64], and malaria [65]. In addition, it has been mentioned as an antimicrobial [66], antidiabetic [54], anti-inflammatory [67], antiprotozoan [68], antioxidant, insecticide [69], larvicide [70], and anticancer [71]. Although these uses of $A$. muricata strongly imply the presence of bioactive compounds with medical benefits, a full insight into the potential of A. muricata in the treatment of disease will require the identification of specific bioactive compounds and a scientifically rigorous demonstration of their ability to improve health outcomes.

\section{Anticancer Effects}

More than $47 \%$ of current anticancer drugs on the market are natural products, their derivatives or natural product 
TABLE 1: Different solvent extracts of A. muricata and their reported anticancer activities.

\begin{tabular}{|c|c|}
\hline Extract (solvent) & Cancers (cell lines) \\
\hline$n$-Hexane & Cervical (HeLa) cancer [37] \\
\hline Chloroform & Cervical (HeLa) cancer [37] \\
\hline Pentane & Melanoma (A375) cancer [36] \\
\hline$n$-Butanolic & (MDA-MB-435S) cancer [89], now known as a melanoma cell line [90] \\
\hline DMSO & Pancreatic (Capan-1 [92], FG/COLO357, and CD18/HPAF [28]) cancer \\
\hline Fungal strain & $\begin{array}{l}\text { Breast (MCF-7) [38], colorectal (HTC-8) [38], lung cancer (A549) [38], } \\
\text { hepatic (Bel-7402) [38], gastric (BGC-823) [38], and ovarian (A2780) [38] cancers }\end{array}$ \\
\hline $\mathrm{H}_{2} \mathrm{O}$ & $\begin{array}{l}\text { Squamous cell carcinoma (SCC-25) [91], melanoma (A375) [36], } \\
\text { prostate (PC-3) [21], pancreatic (CD18/HPAF) [28], and breast cancer patients [118] }\end{array}$ \\
\hline Hexane & $\begin{array}{c}\text { Breast (MCF-7 and MDA-MB-231) [31], colorectal (HT-29 and HCT-116) [26], lung cancer (A549) [31], } \\
\text { leukemic (U-937) [33, 46], pancreatic (Capan-1) [92], and hepatic (Hep G2) [31] cancers }\end{array}$ \\
\hline Ethyl acetate & $\begin{array}{c}\text { Breast (MCF-7 and MDA-MB-231) [31], colorectal (HT-29 and HCT-116) [25], lung (A549) [31], } \\
\text { leukemic (U-937) [33, 46, 131], hepatic (Hep G2) [31], and cervical (HeLa) [37] cancers. }\end{array}$ \\
\hline Ethanol & $\begin{array}{c}\text { Ehrlich ascite carcinoma (EACC) [93], breast (MCF-7 [45], MDA-MB-231-BCRP clone } 23 \text { [77, 139], T47D [22], } \\
\text { MDA and SKBR3 [93]), colorectal [20] [140] (COLO-205 and DLD-1) [94], lung (H-460) [45, 95], } \\
\text { leukemic (K562 [19] [96], ECV304 [96] and HL-60 [27]), stomach (C-678) [95], } \\
\text { melanoma (A375) [36], skin [141], glioma (SF-268) [45], and cervical (HeLa) [37] cancers }\end{array}$ \\
\hline Methanol & $\begin{array}{c}\text { Breast (MCF-7 and MDA-MB-231 [31], MDA-MB-231-pcDNA3, and MDA-MB-231-BCRP } \\
\left.\text { clone } 23 \text { [24]), colorectal (HT-29 and HCT-116 [26], HCT116 }\left(p 53^{+/+}\right) \text {, and HCT116 }\left(p 53^{-/-}\right)[24]\right), \\
\text { lung (A549 [31] and NCI-H292 [113]), leukemic (U-937 [33, 46], CCRF-CEM, and CEM/ADR5000 [24]), } \\
\text { hepatic (Hep G2 [24, 31] and Hep 2,2,15 [31]), glioma (U87MG and U87MG.AEGFR) [24], } \\
\text { and laryngeal (currently cervical HeLa; Hep-2) [113] cancers }\end{array}$ \\
\hline
\end{tabular}

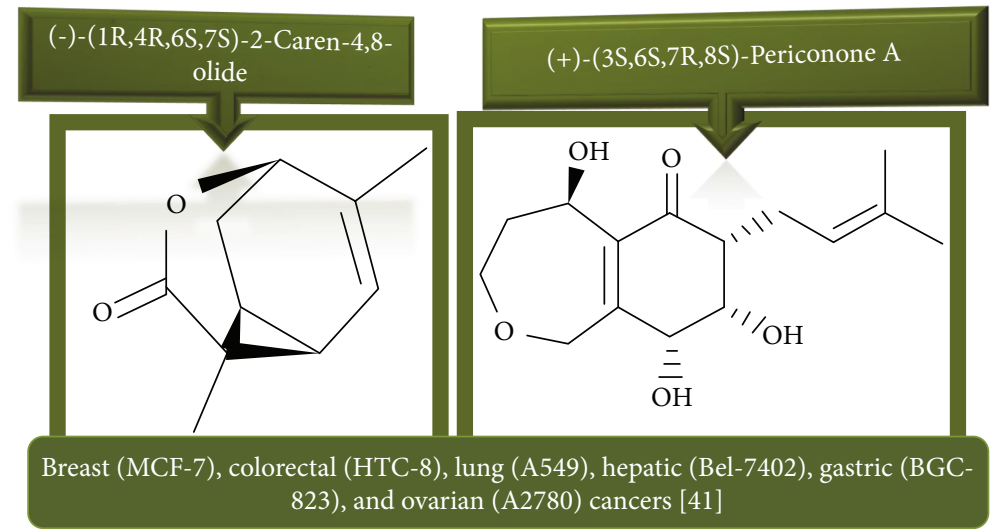

Figure 1: Chemical structure of compounds derived from fungal strain extracts and the cancers sensitive to them.

synthetic mimics, and more than 25,000 identified phytochemicals have been shown to possess potent anticancer activities [72, 73]. The aerial parts of graviola have been extensively studied with several reported in vitro and in vivo pharmacological activities, and have been shown to be effective in the management of several cancer types. The detailed molecular mechanisms of action of various graviola organs against various cancers are summarized in tabular format (Table 3 and Figure 3).

\section{Cytotoxicity}

There is no universal definition for the term "cytotoxic drug." Nonetheless, this term is commonly used in a variety of regulations for pharmaceutical development and manufacturing of drugs [74]. Simply put, a cytotoxic drug is an agent that has destructive actions on cells, often implying that these cells are targeted for destruction [75], a concept that certainly applies to many antineoplastic drugs [75].

The major bioactive components that have been extracted from various $A$. muricata's parts are known as annonaceous acetogenins (AGEs). These are derivatives of long-chain (C32 or C34) fatty acids derived from the polyketide pathway, reviewed in [76]. Many of these derivatives are reported to be selectively toxic to cancer cells, including multidrug-resistant cancer cell lines [77]. Annonaceous acetogenins induce cytotoxicity, at least in part, by inhibiting mitochondrial complex I, which is involved in oxidative phosphorylation and ATP synthesis [78]. As cancer cells have a higher demand for ATP than the normal cells, mitochondrial complex I inhibitors have potential in cancer therapy [79]. 


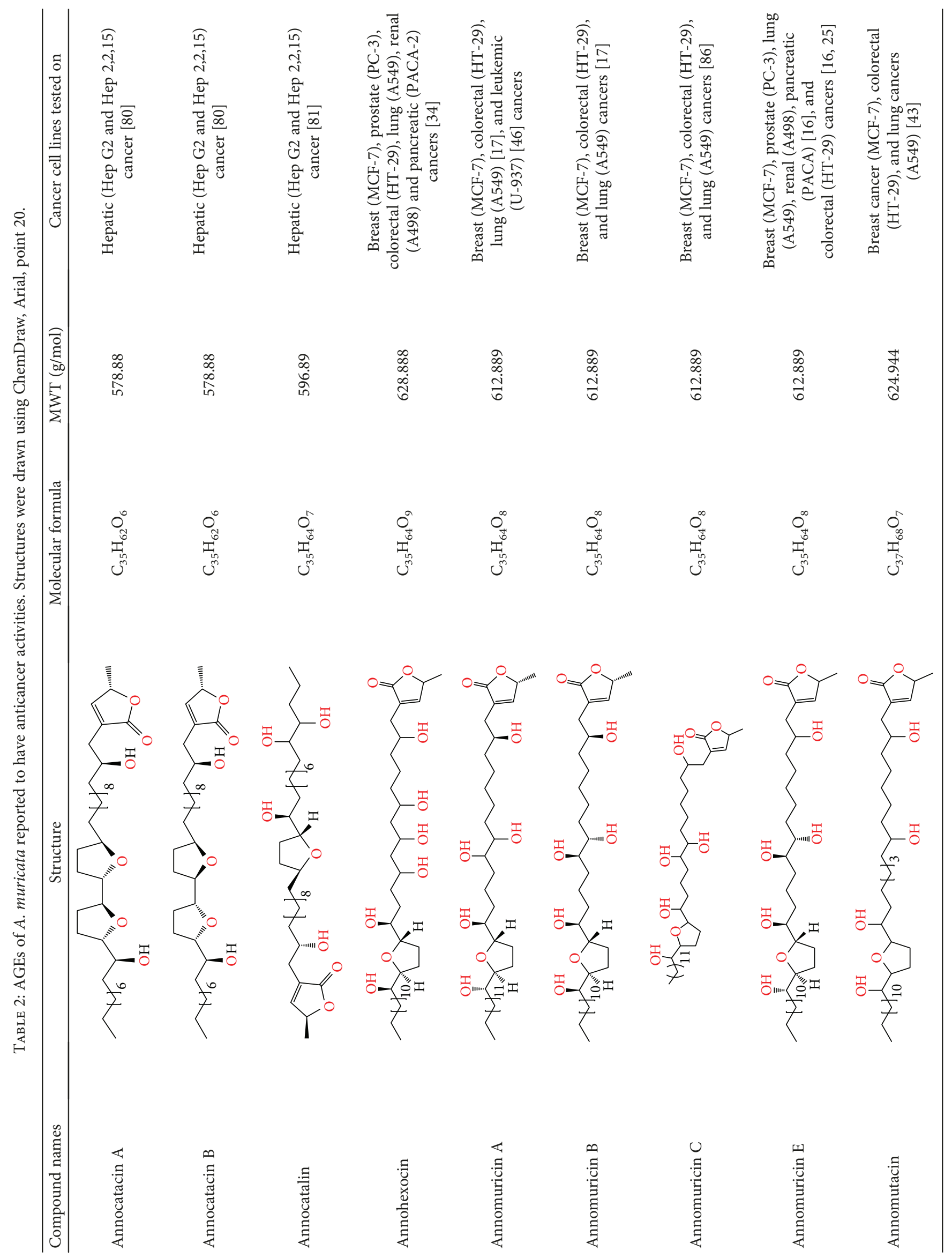




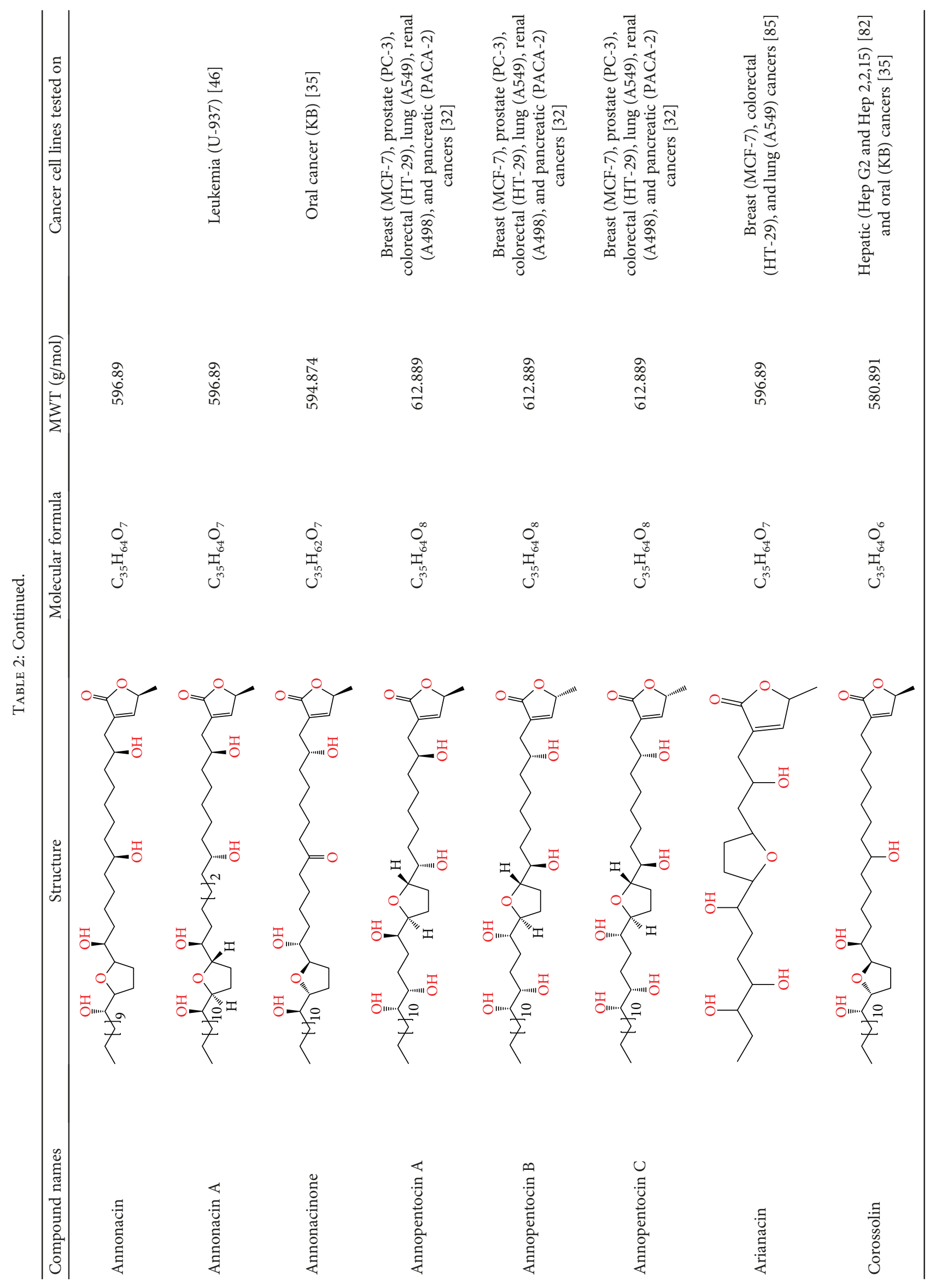




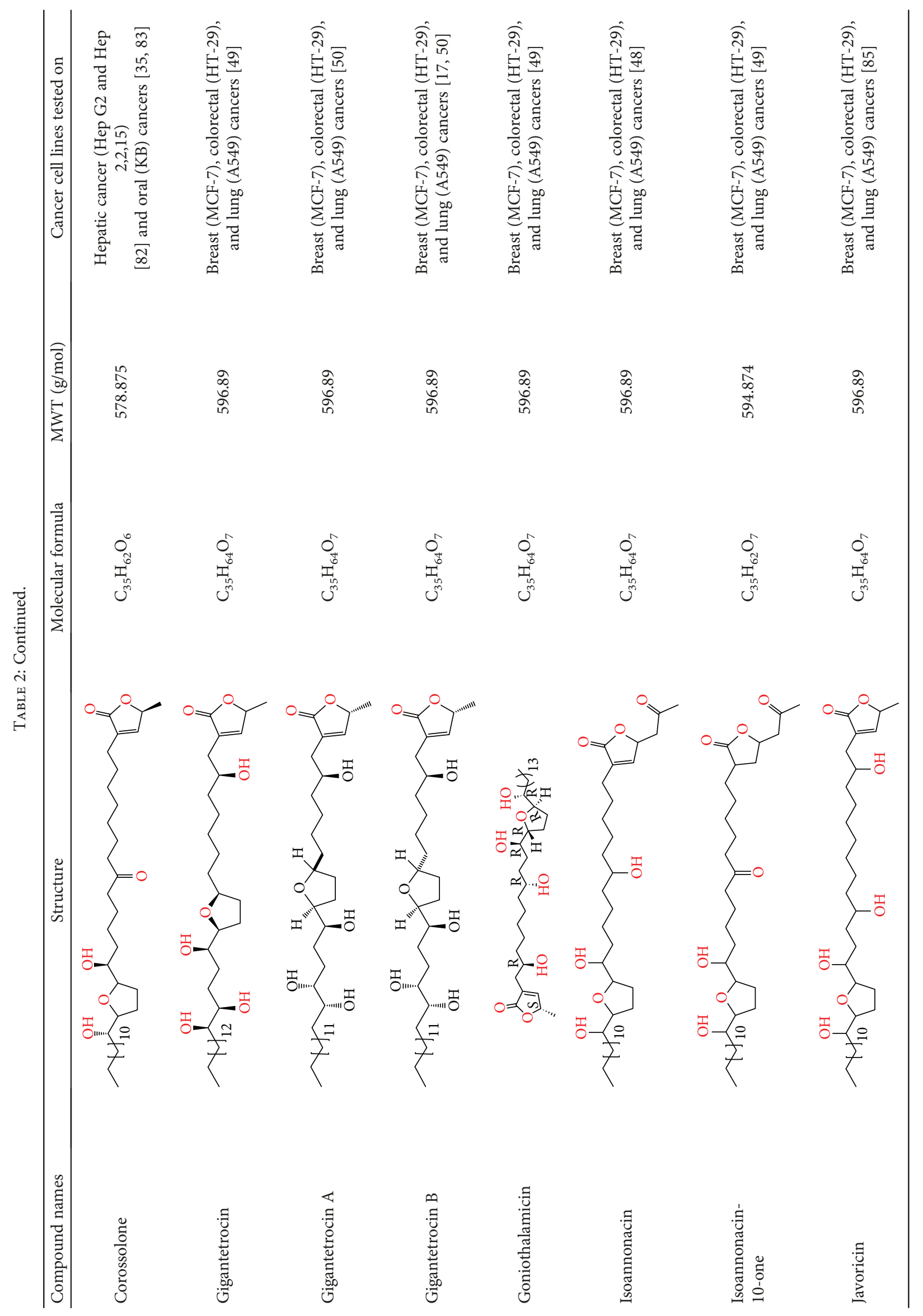




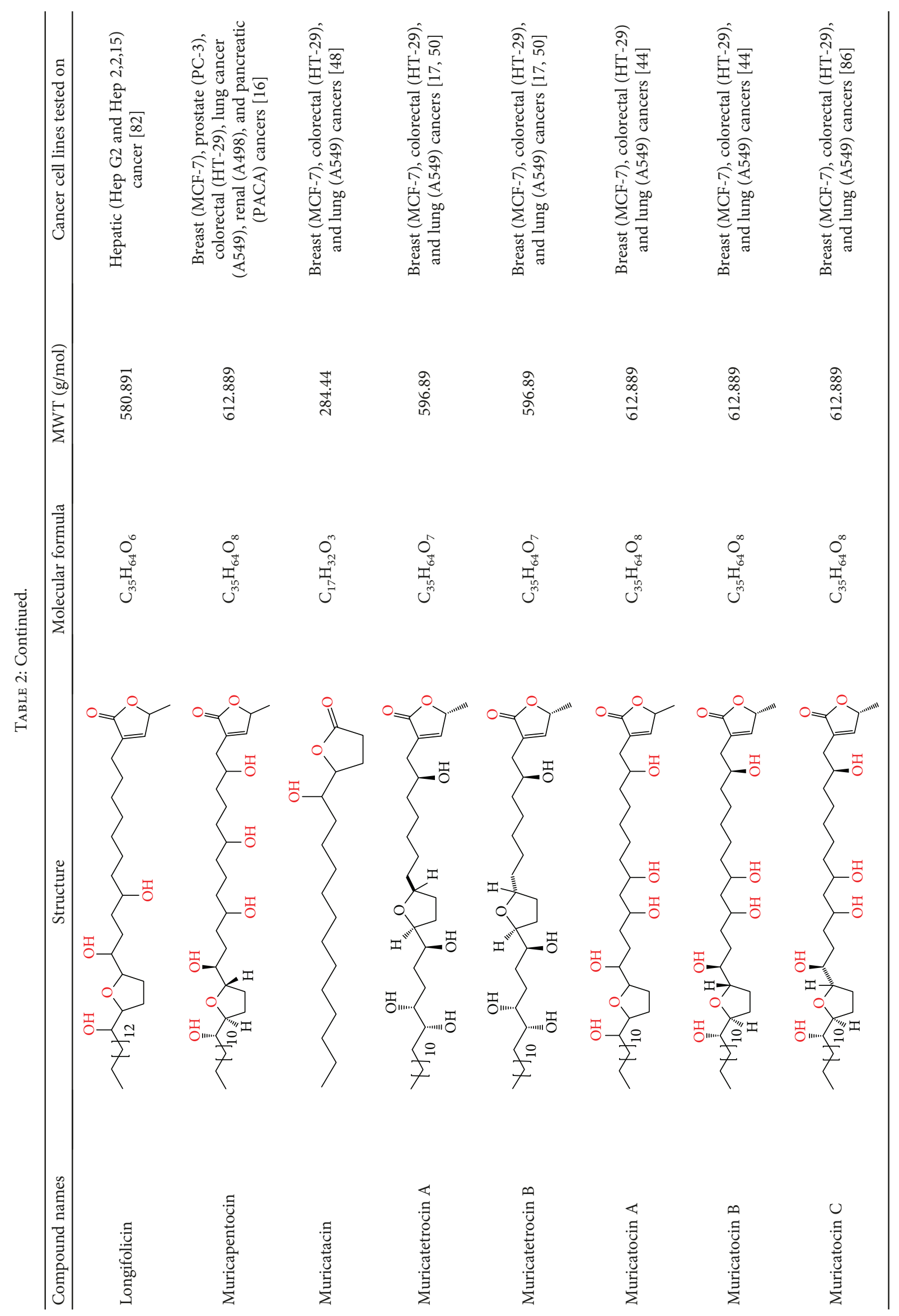




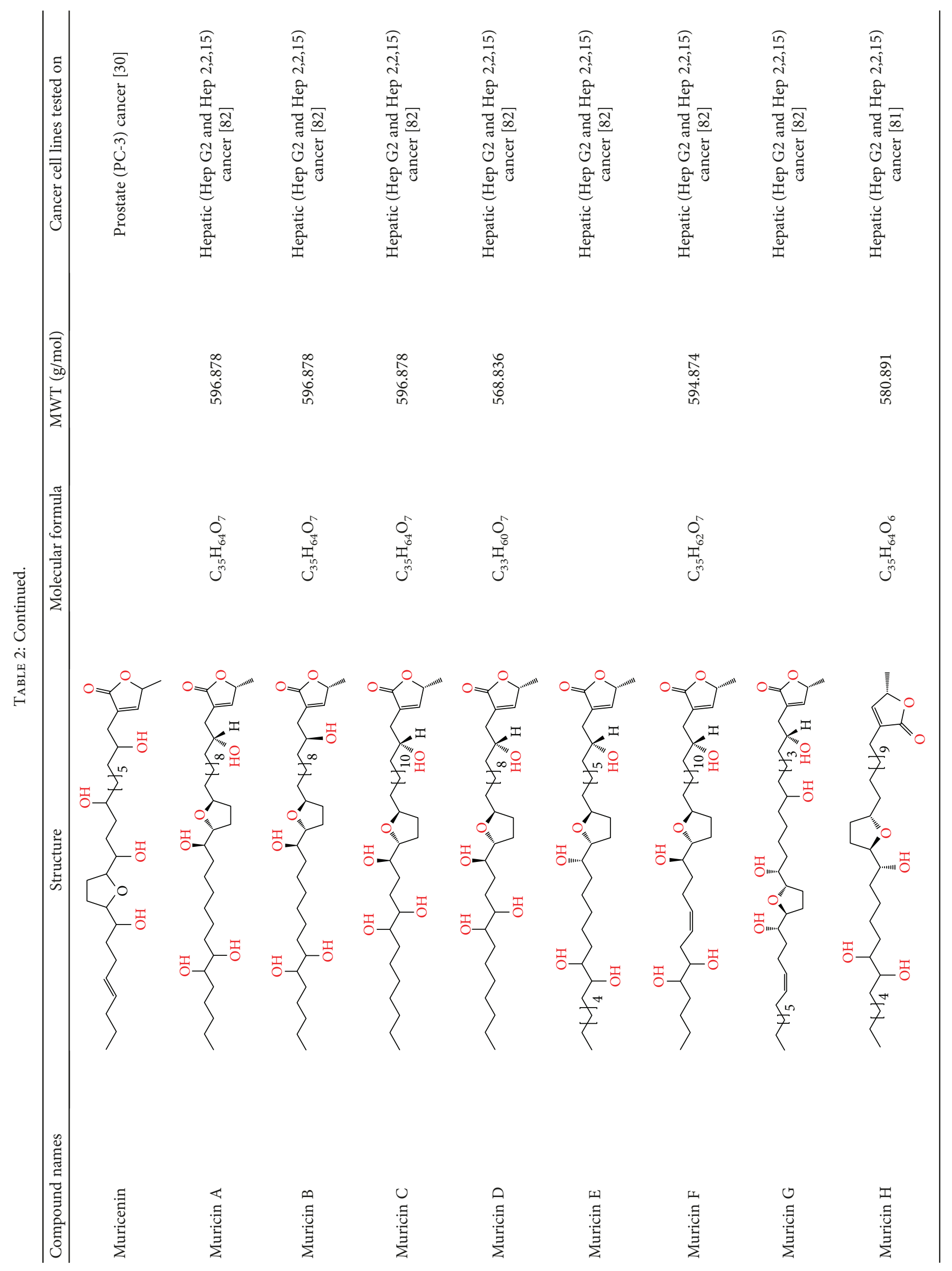




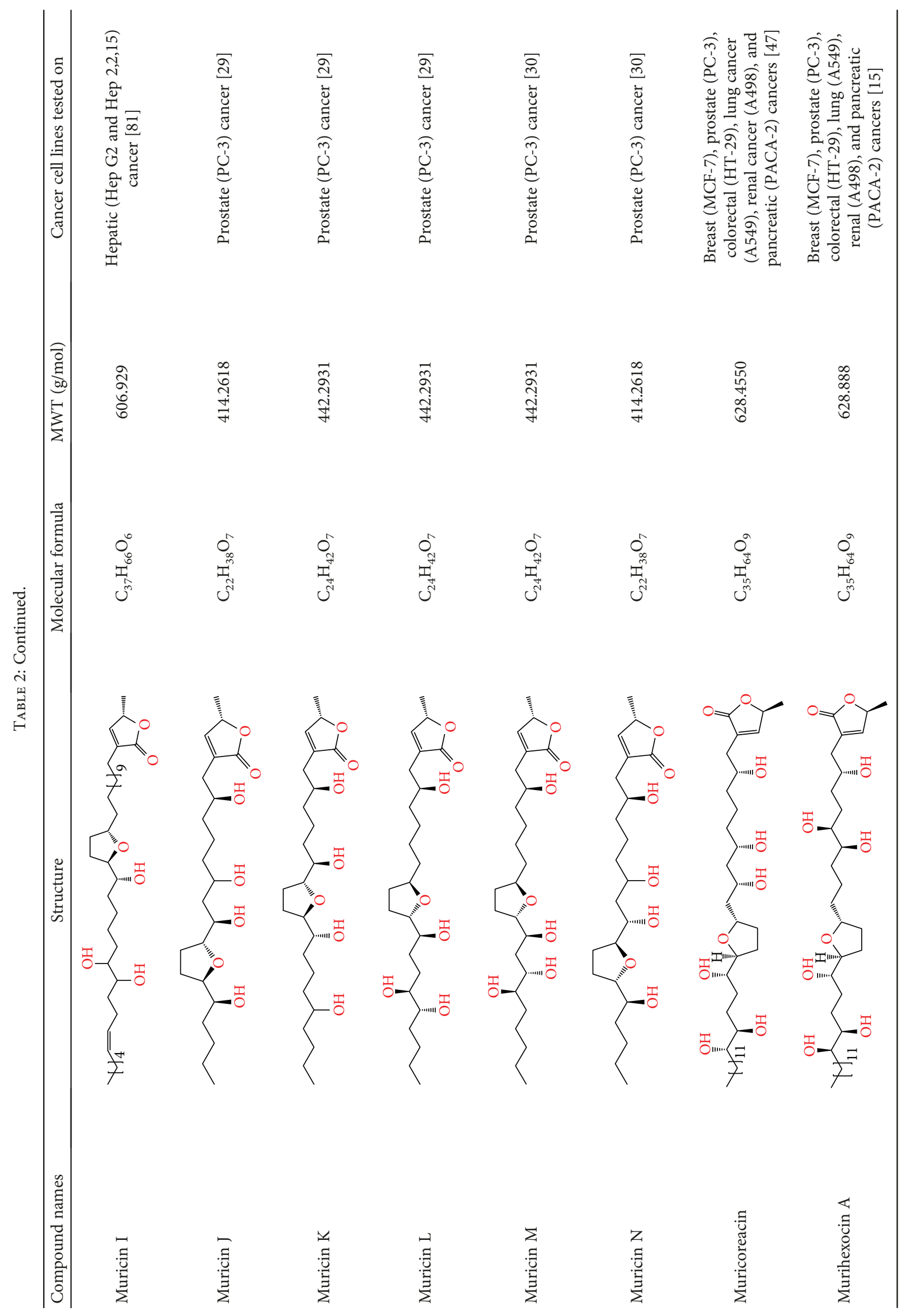




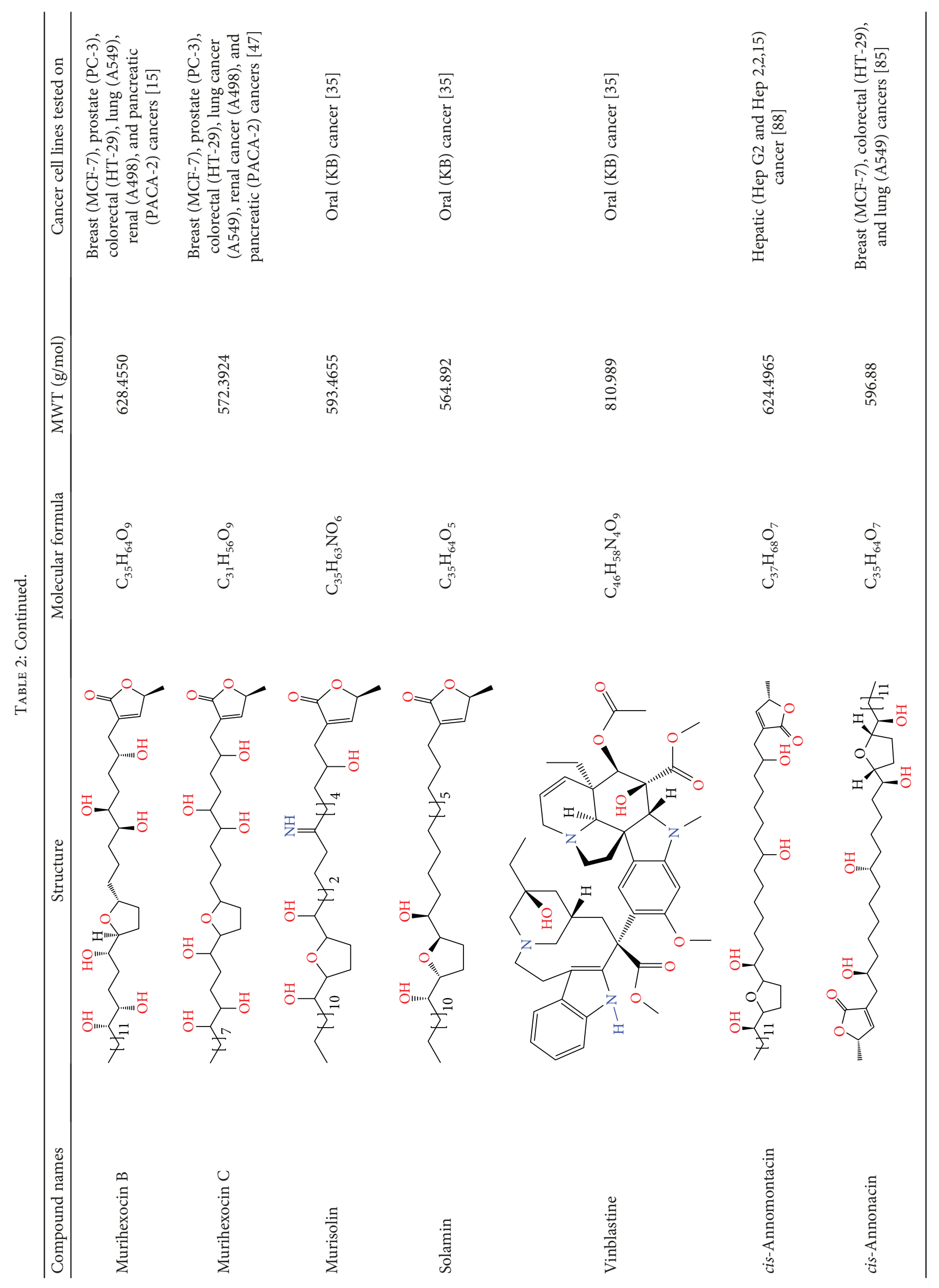




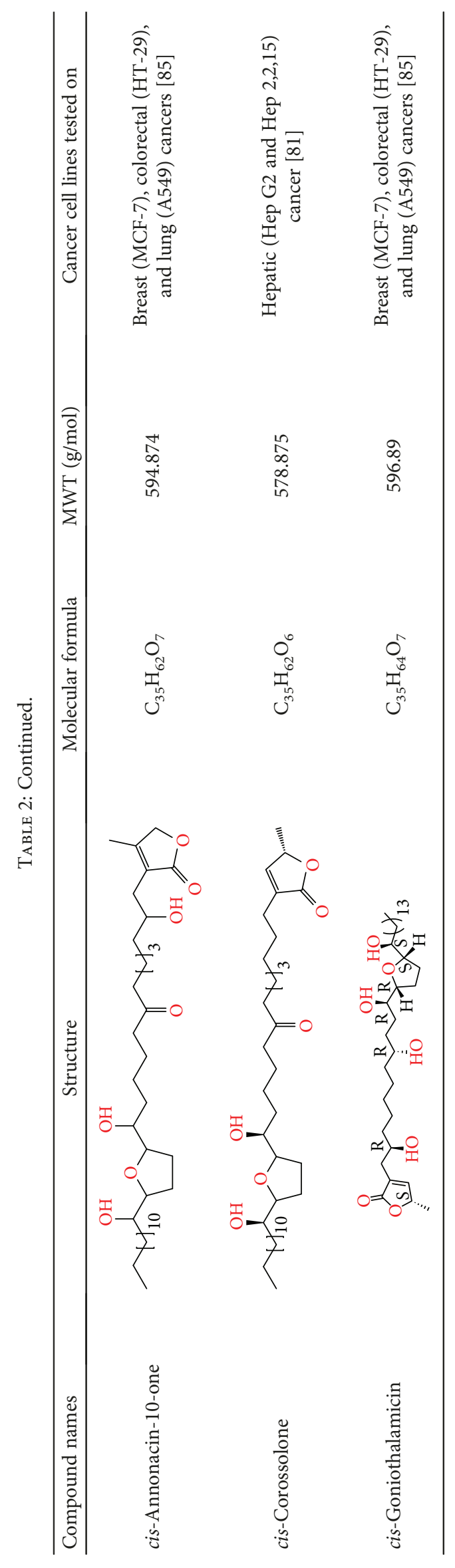




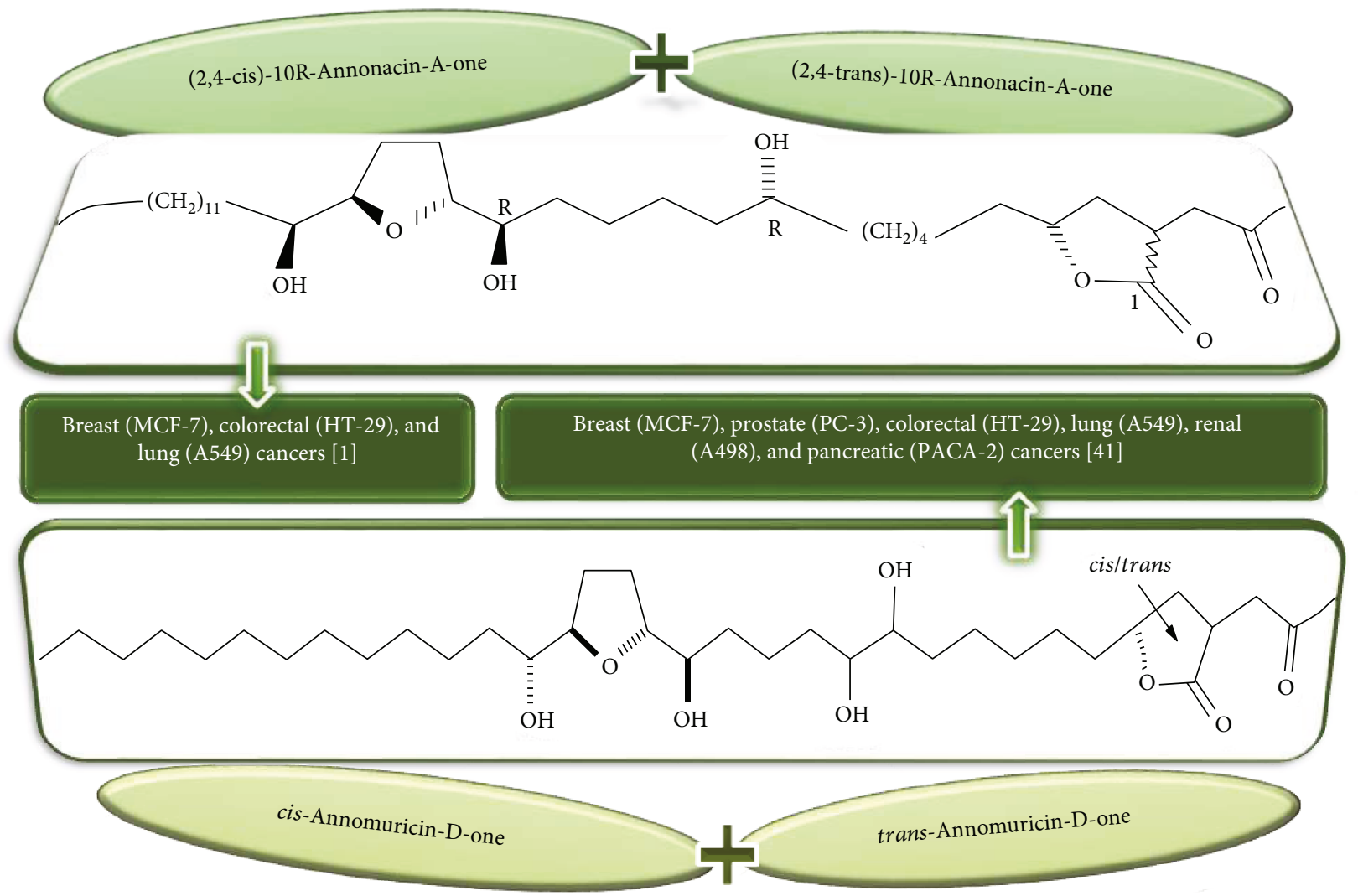

Figure 2: Chemical structures of two AGE combinations along with their targeted cancer phenotype.

Purified AGEs, such as annocatacin (A or B) [80] or annocatalin [81], have been found to induce significant cytotoxicity in Hep G2 and Hep 2,2,15 hepatic cancer cells in vitro [82, 83]. In breast cancer, cytotoxicity can be induced in MCF-7 cells using any of the following purified AGEs: annomuricin A, B [17], C [18], or E [16]; muricatocin A, B, or C [47]; muricapentocin [16]; annomutacin [43]; annohexocin [34]; annopentocin A, B, or C [32]; murihexocin A, B [15], or C [47]; muricoreacin [47]; muricatacin [48]; isoannonacin [49]; isoannonacin-10-one [49]; goniothalamicin [49]; gigantetrocin [49] A or B [50], muricatetrocin A or B [17, 84], cis-annonacin; cis-annonacin-10one; cis-goniothalamicin; arianacin; or javoricin [85]. In addition, synergistic therapeutic effects have been shown with the combination of AGEs. For example, cytotoxicity in breast cancer (Figure 2) has been observed using a combination of (2,4-cis)-10R-annonacin-A-one and (2,4trans)-10R-Annonacin-A-one [43], or a mixture of cisannomuricin-D-one and trans-annomuricin-D-one [32]. Moreover, AGEs induce cytotoxicity in a variety of other cancers such as prostate $[15,16,21,22,34,47]$, colorectal $[16,17,25,32,34,44,86]$, lung $[15-17,32,34,44,47]^{5}$, leukemia [46], renal $[15,16,32,34,47]$, pancreatic [87, 88], hepatic $[35,36]$, and oral $[32,43]$ cancers. Combinations of AGEs also exhibited cytotoxicity in colorectal (HT-29), lung (A549) [32], prostate (PC-3), renal (A498), and pancreatic (PACA-2) cancers [28].

Organic solvent extracts derived from the different parts of A. muricata (presumably containing multiple bioactive compounds) have also been shown to induce cytotoxicity in a variety of cancer cell lines. For example, leaf extracts induced cytotoxicity in human A375 melanoma [36], immortalized HaCaT keratinocytes, and MDA-MB-435S, previously cross-contaminated and mislabeled as breast carcinoma cells [89], but currently identified and authenticated as a melanoma cell line (M14) [56, 90], or head and neck squamous cell SCC-25 carcinoma [91], pancreatic (CD18/HPAF and FG/COLO357) [28], colorectal (HT-29 and HCT-116) [25], Liver HepG2 [56], and lung A549 [31] cancer cell lines. Leaf extracts have also demonstrated reduced cell viability in pancreatic Capan-1 cancer cells [92]. Extracts derived from seeds are toxic to hepatic Hep G2 [31] cancer cells, while extracts from leaf, pericarp, seed, and stem have each shown cytotoxicity towards hematological malignant cells such as the leukemia U-937 cell line [56, 69].

The most commonly used solvents for the A. muricata extracts that induced cytotoxicity against cancer cells are ethanol and methanol (Table 3). Ethanolic leaf extracts induce cytotoxicity in breast MCF-7 [45] and MDA [93], colorectal COLO-205 and DLD-1 [94], lung H-460 [95], leukemic K562 [19] and ECV-304, also previously misidentified as a human umbilical vein endothelial cell line [96], but now re-authenticated as a T24-contaminated human bladder cancer cell line [90, 97, 98] and (see http://iclac. org/databases/cross-contaminations), stomach C-678 [95], melanoma A375 [36], and Ehrlich ascite EACC [93] cancer cells. However, according to available data, ethanolic 


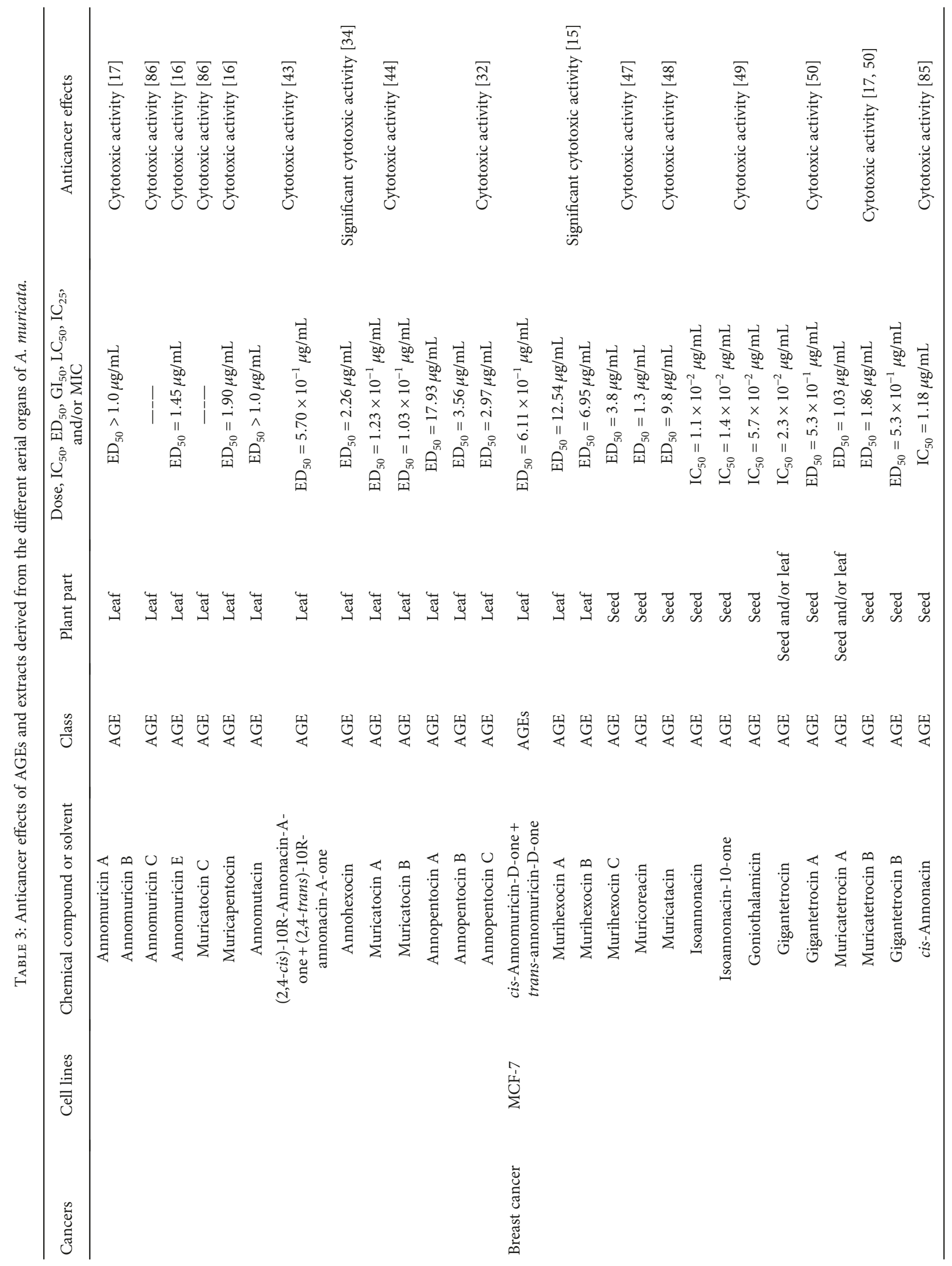




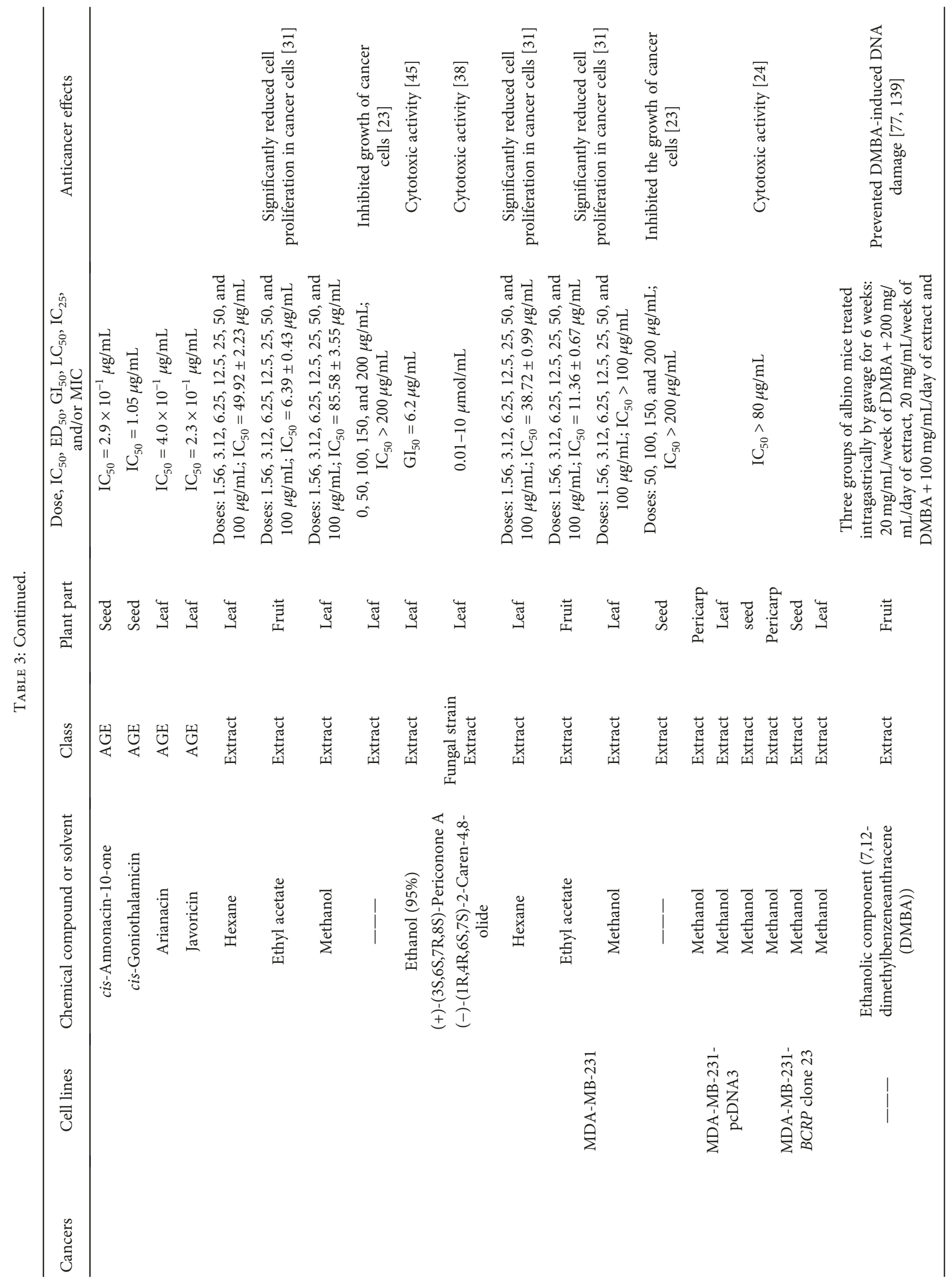




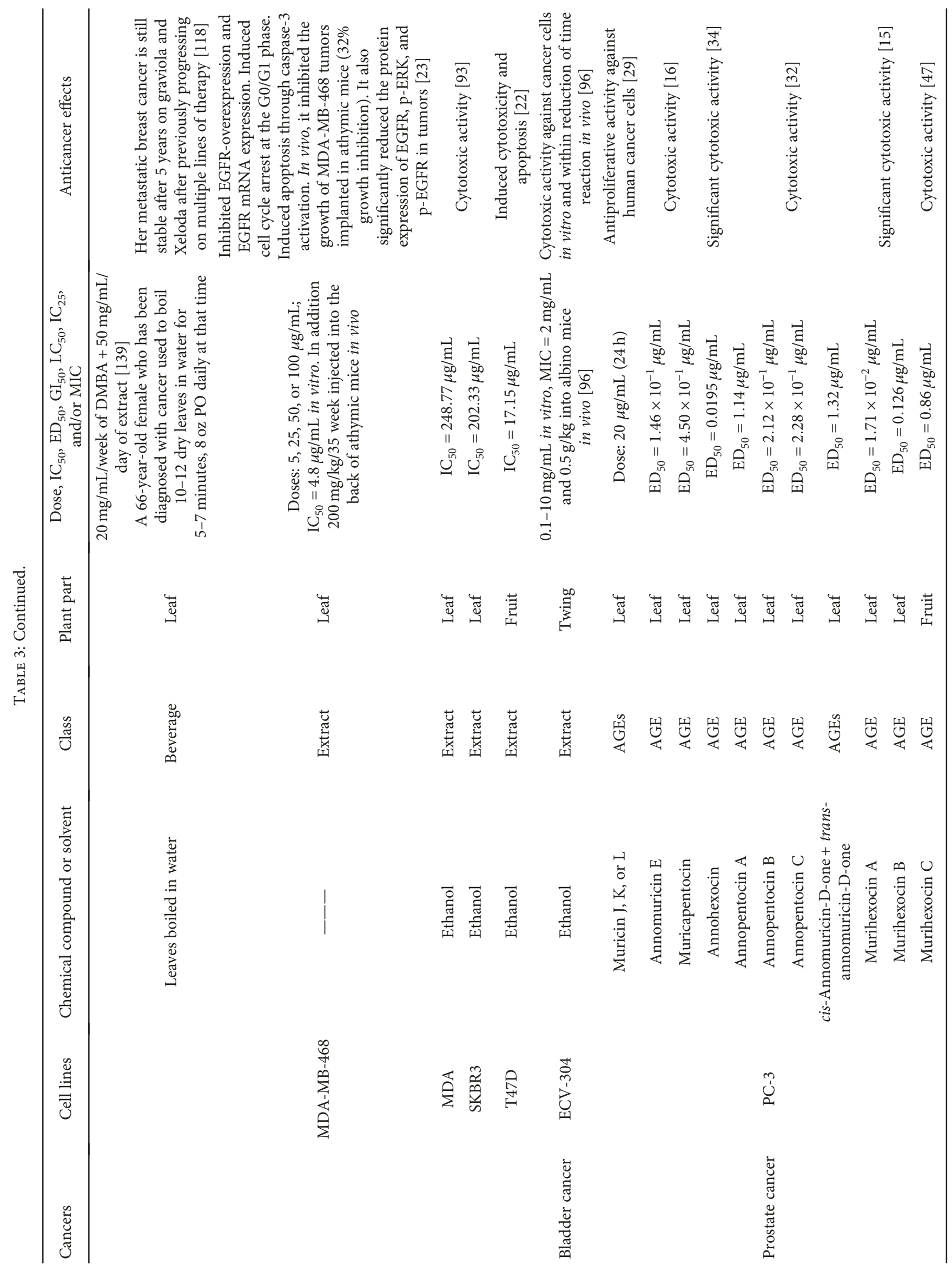




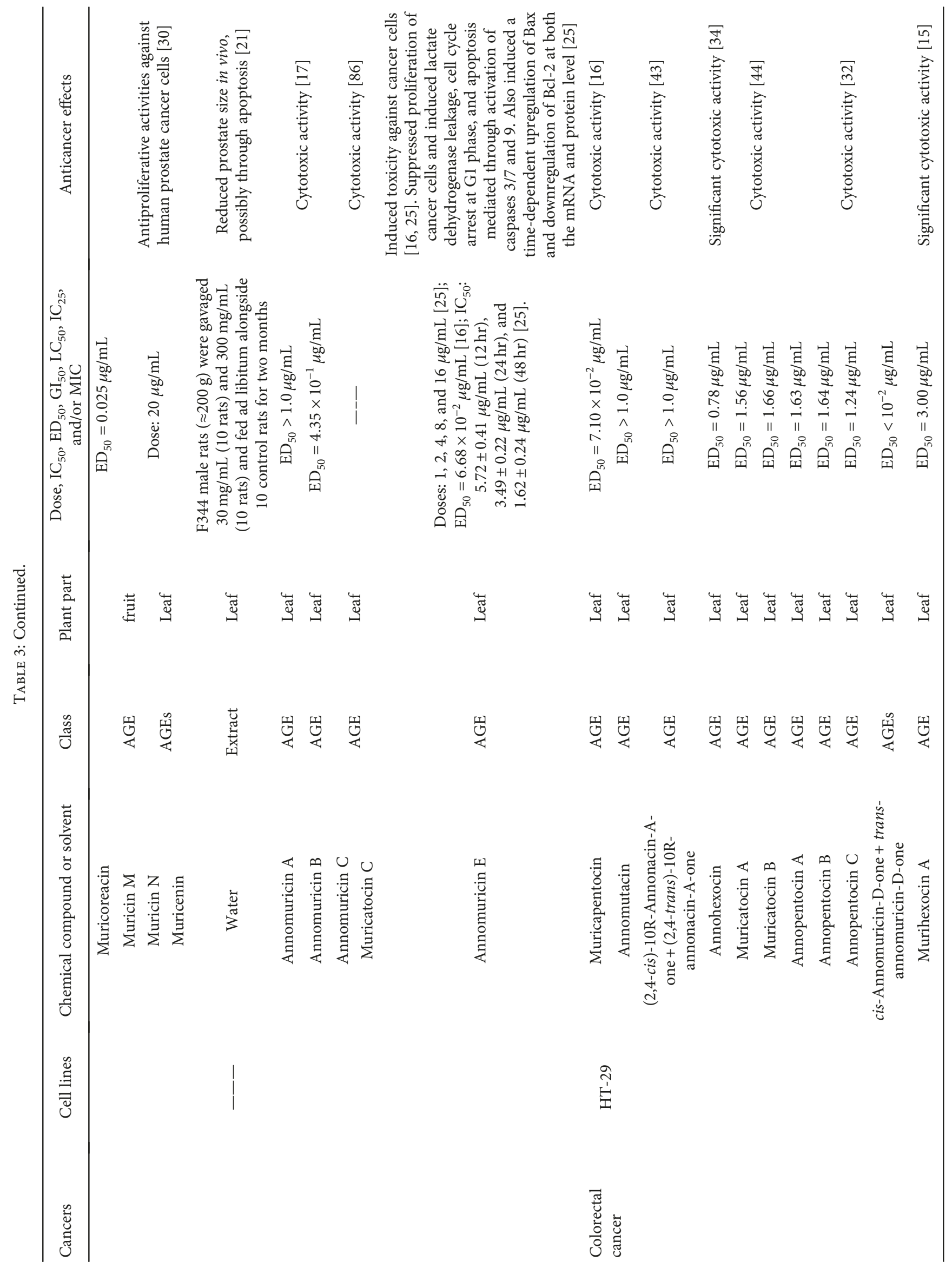




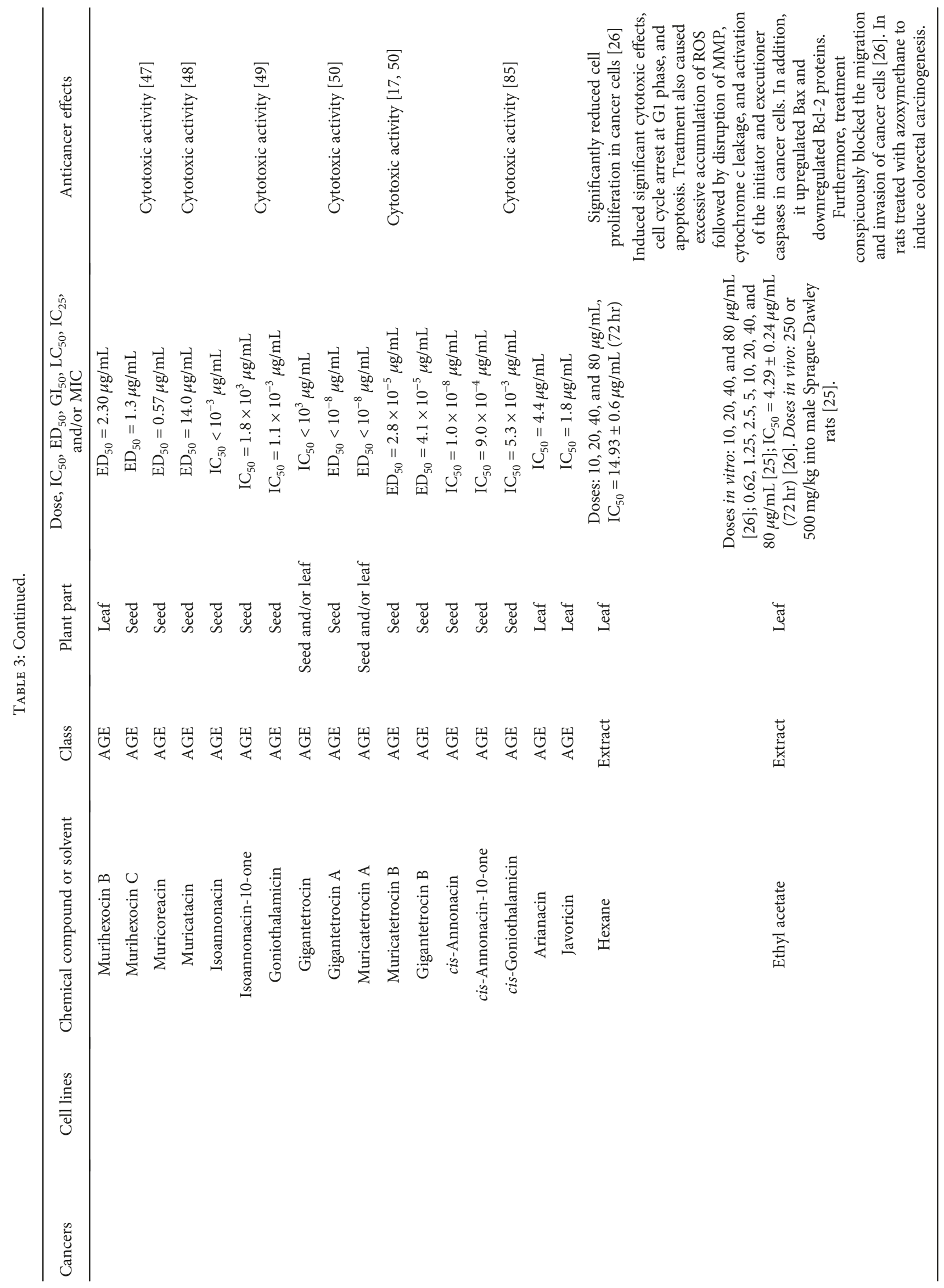




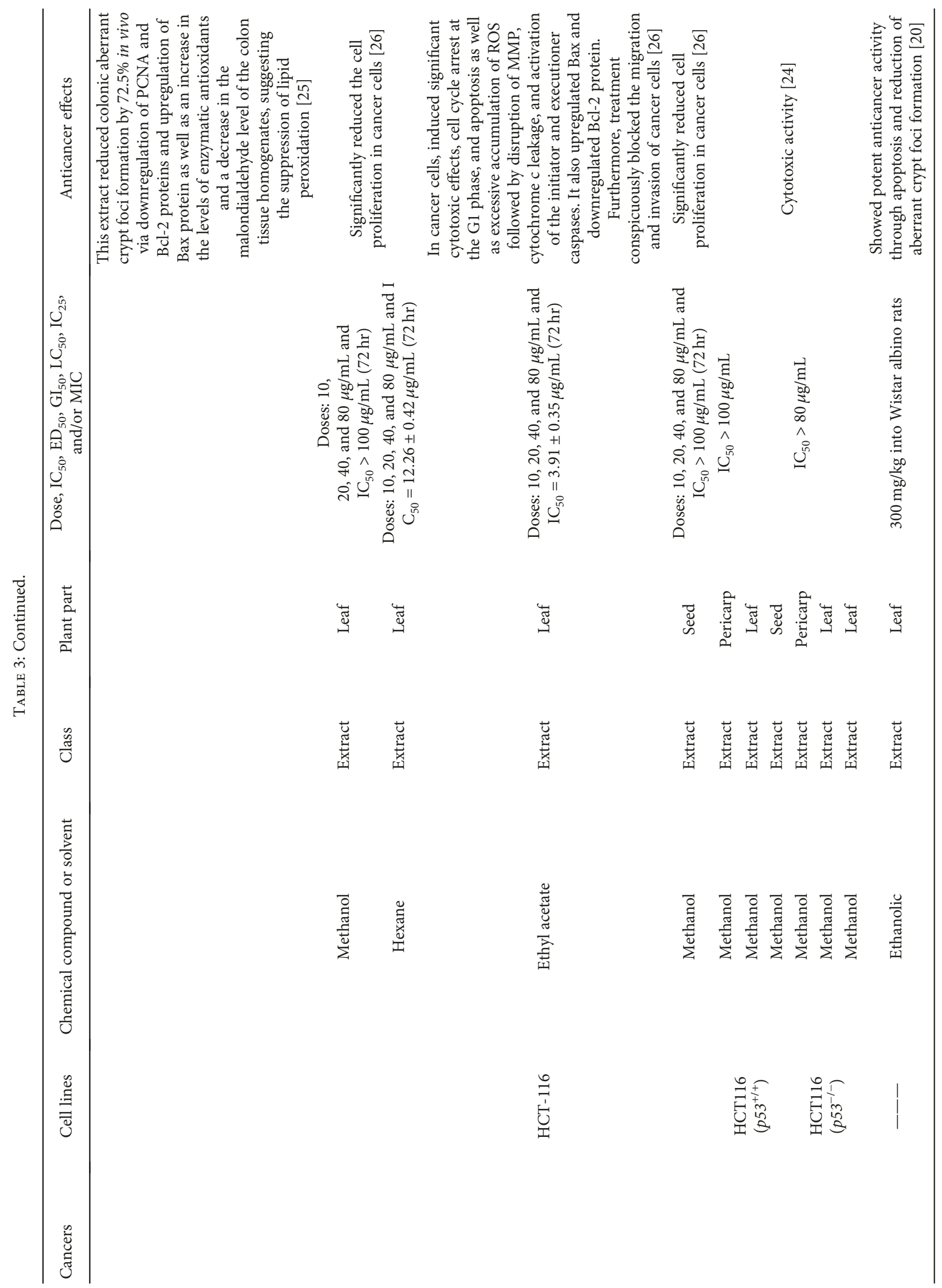




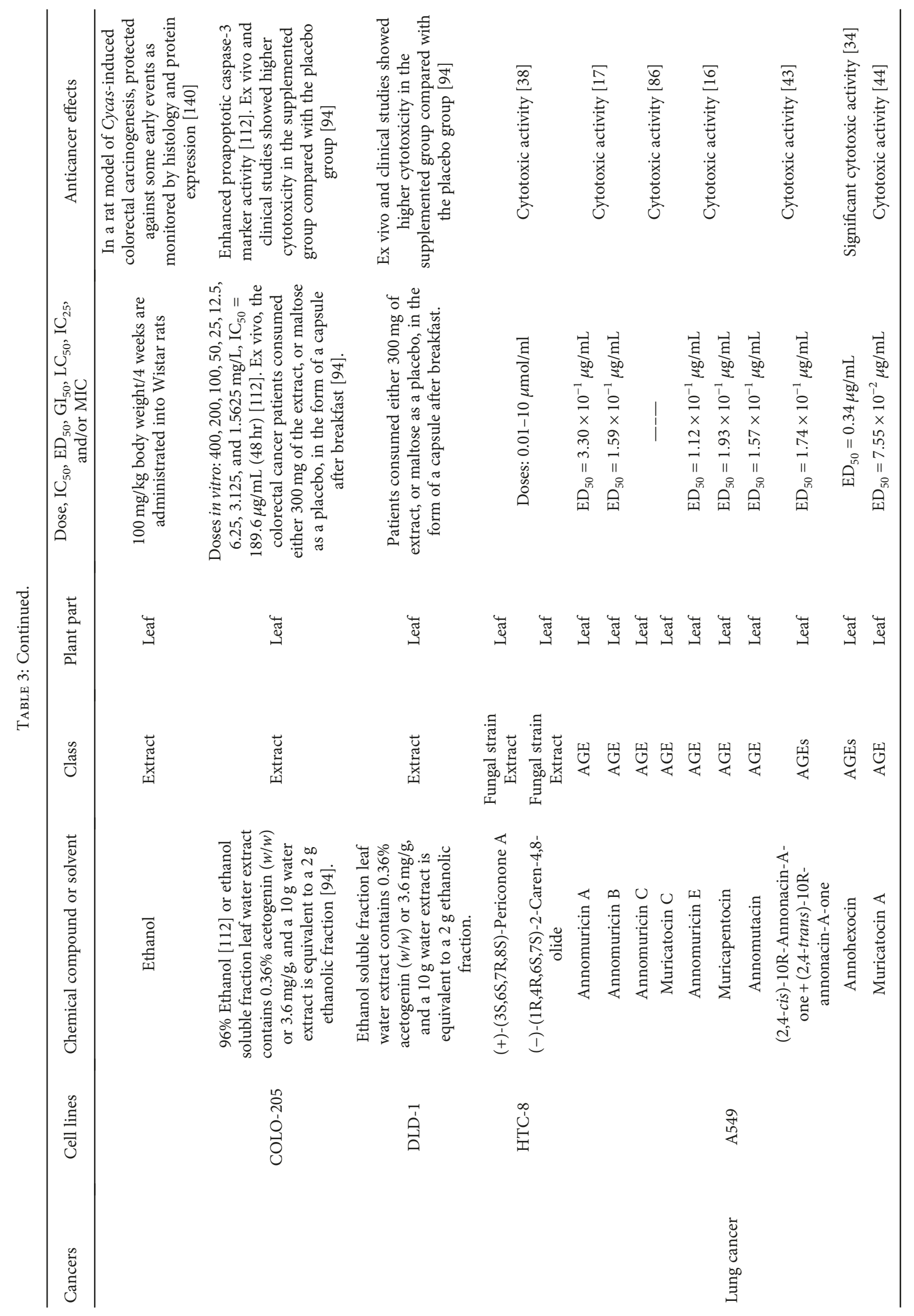




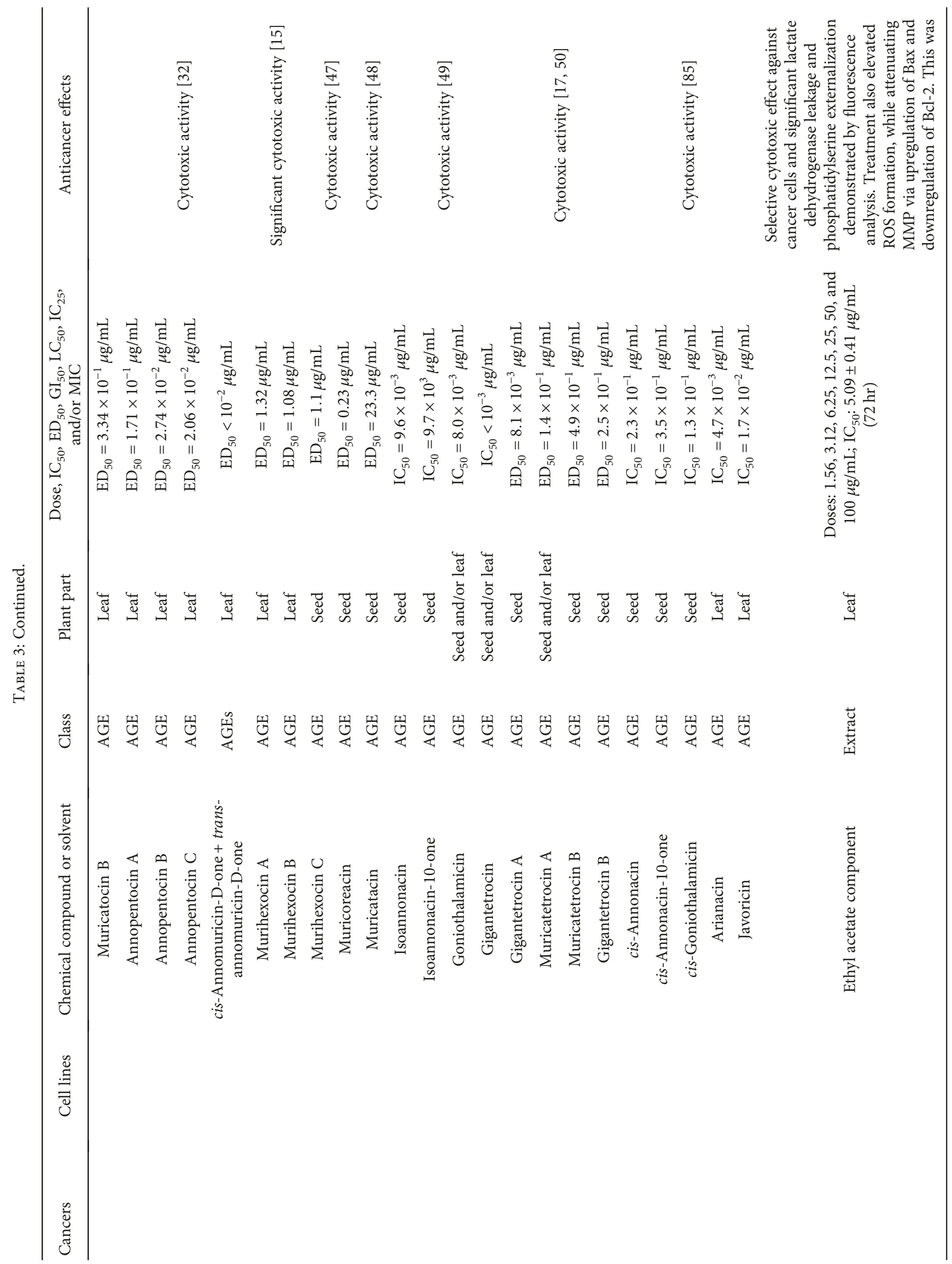




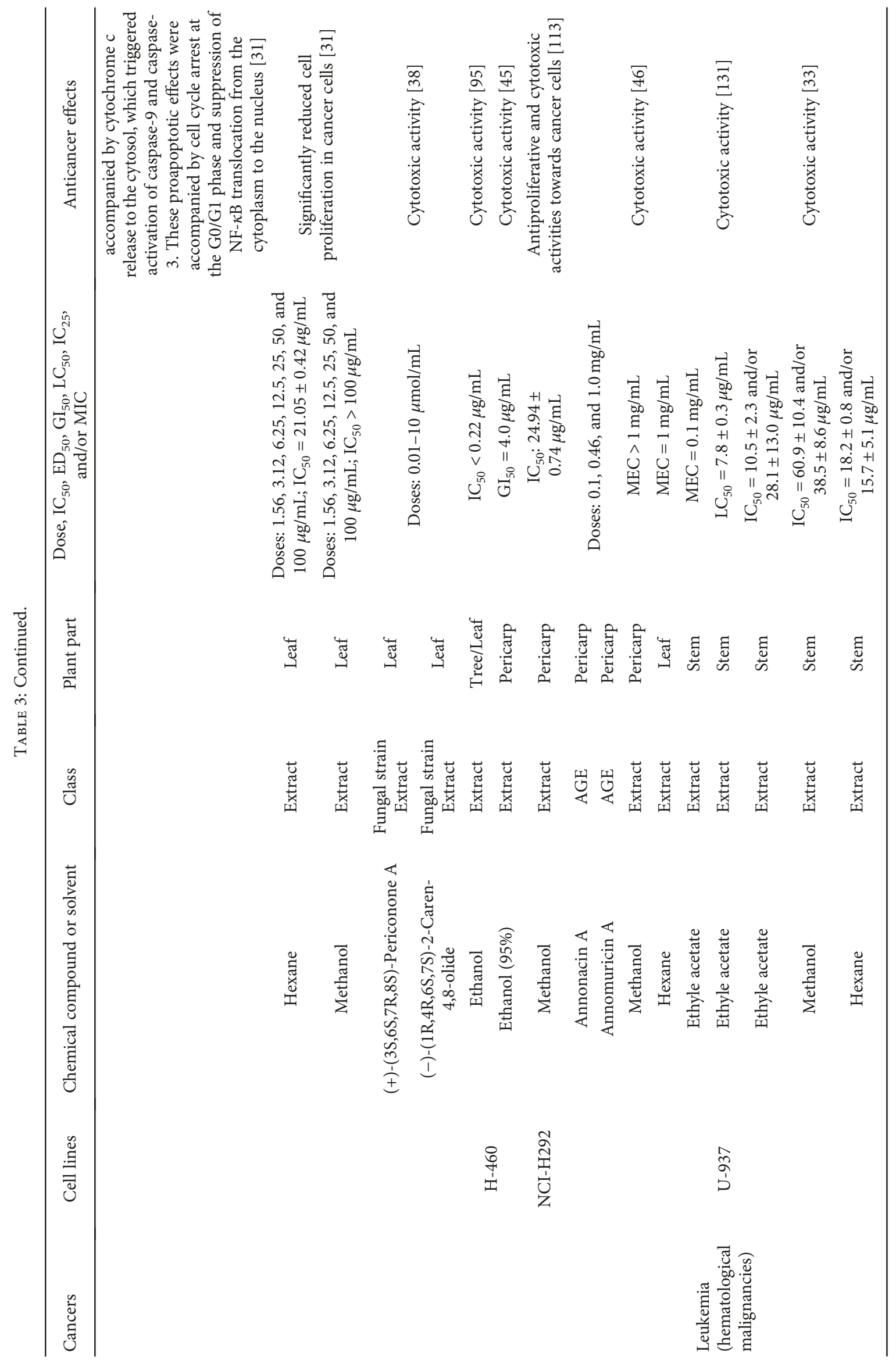




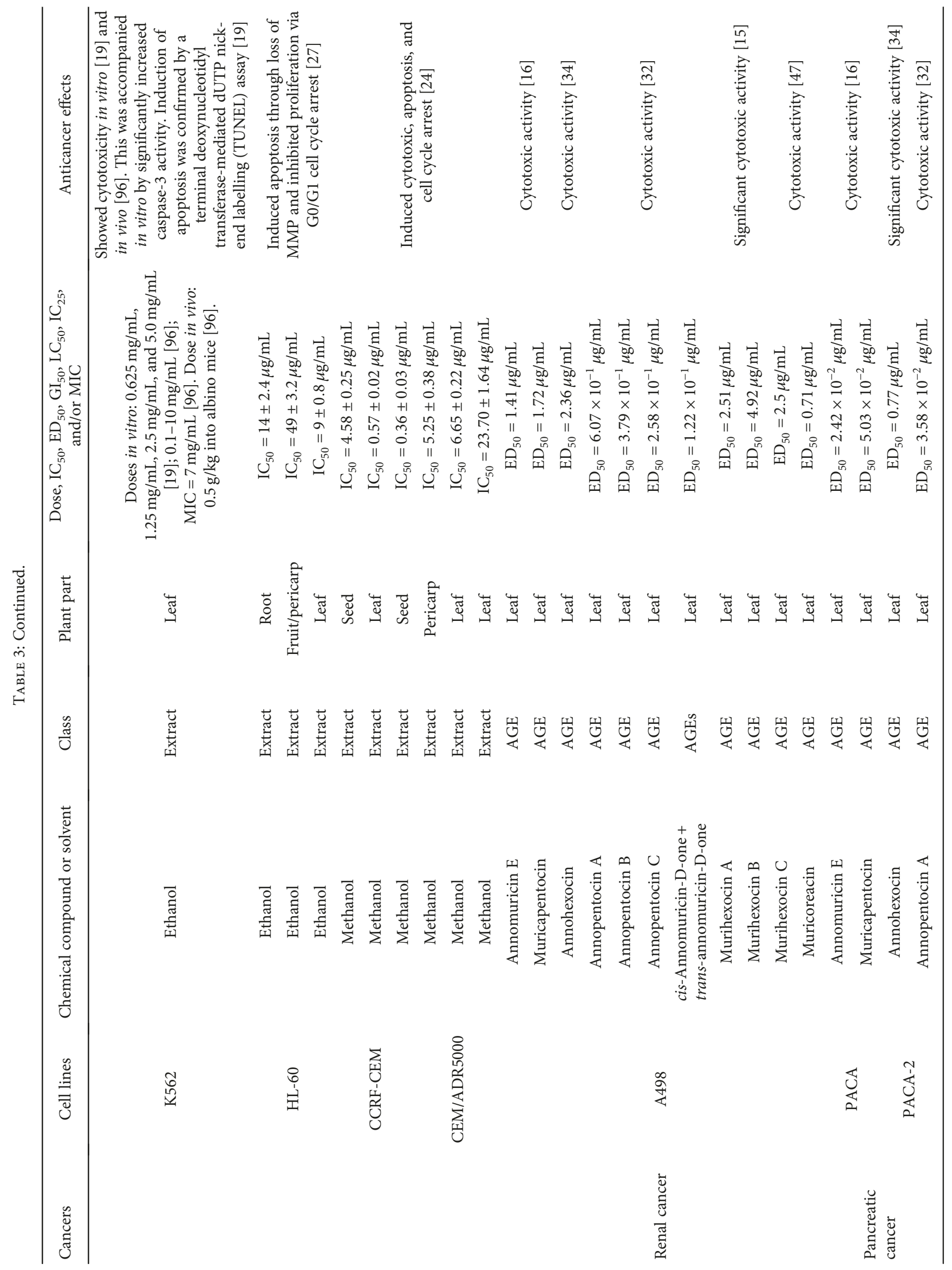




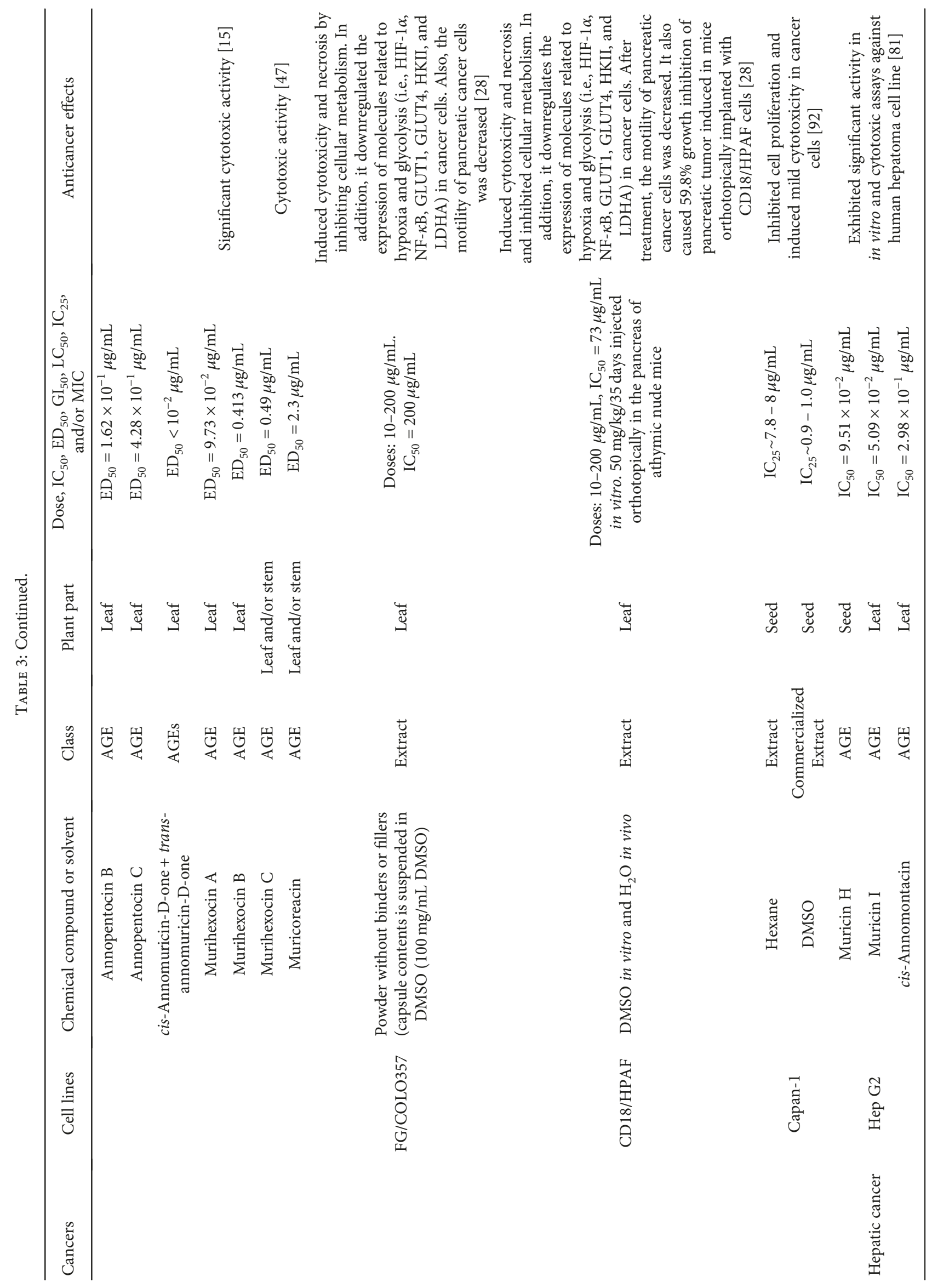




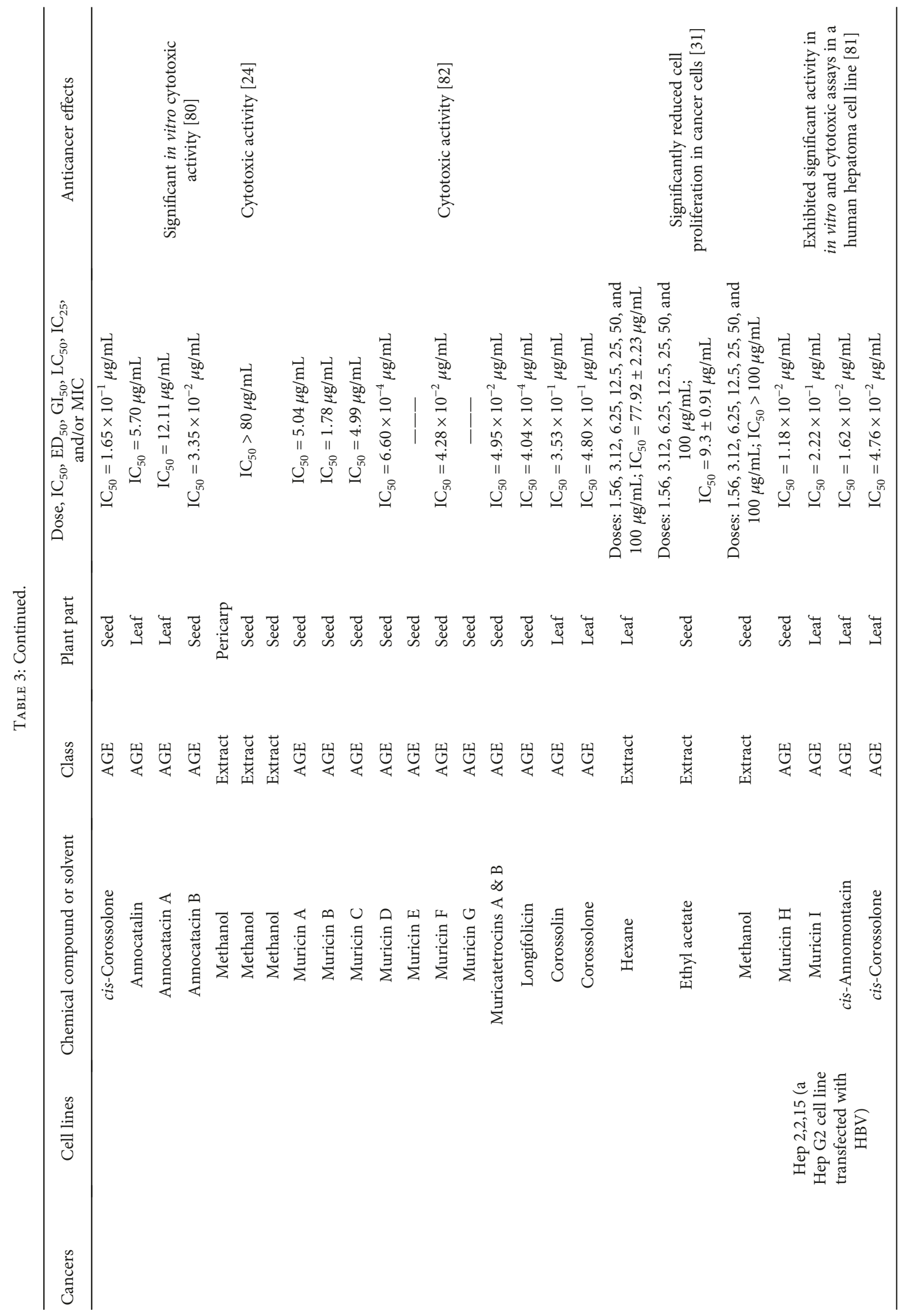




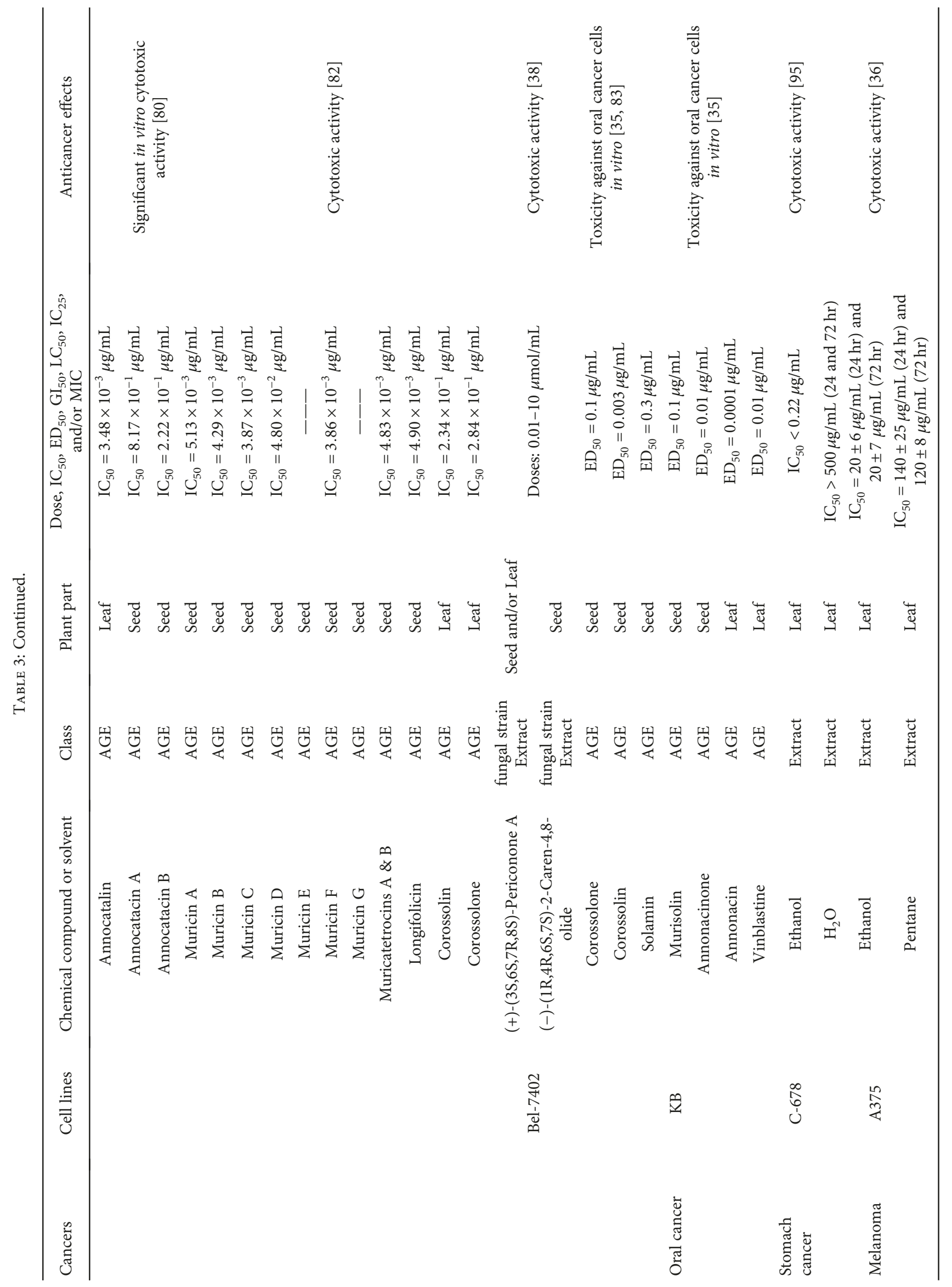




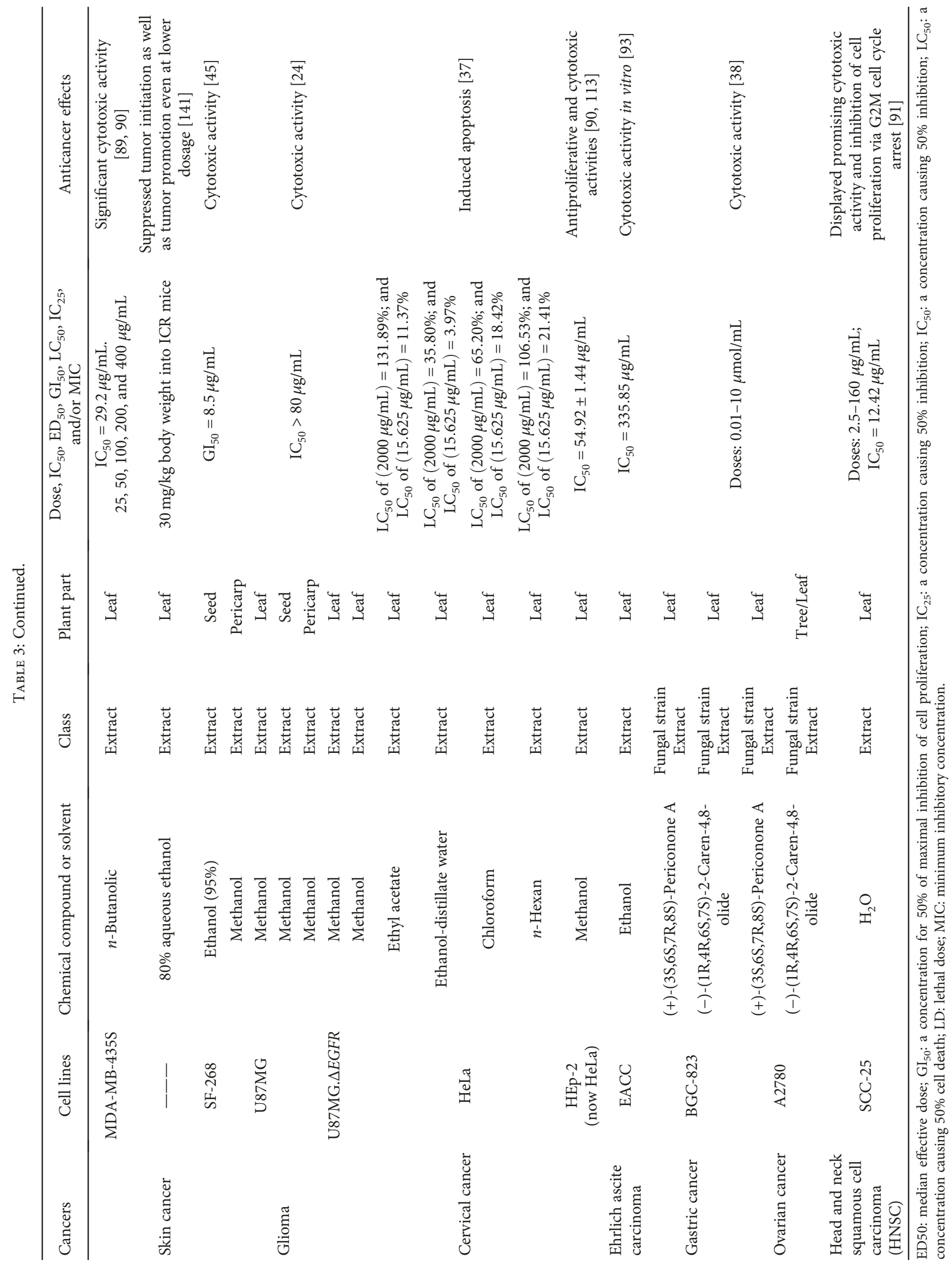




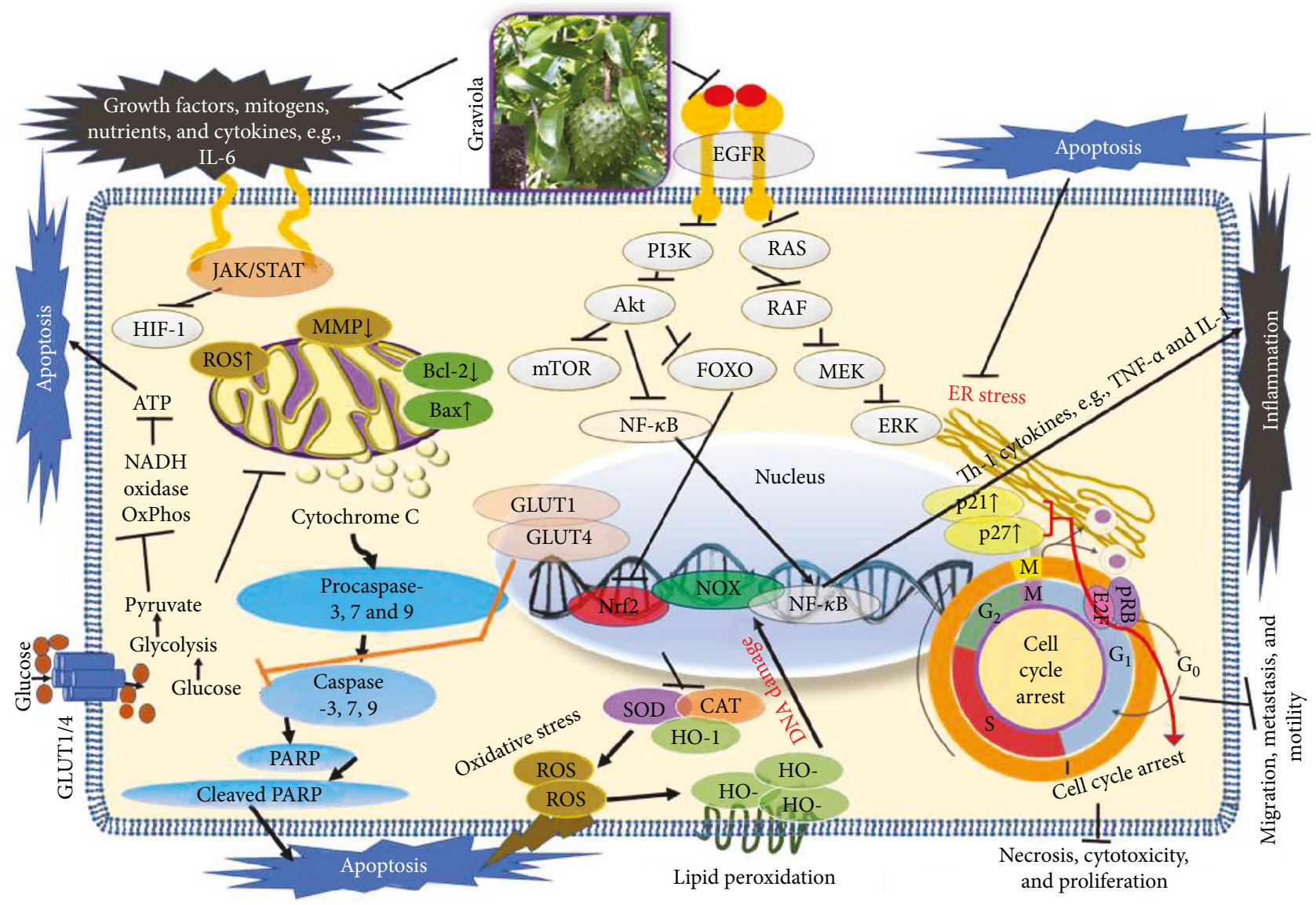

Figure 3: Overview of the molecular actions of $A$. muricata (graviola) leading to anticancer and other health benefits. Extracts of the different aerial parts of $A$. muricata using several solvents have been shown to induce cytotoxicity, cell cycle arrest, apoptosis, and necrosis and, conversely, to inhibit cancer cell motility, migration, metastasis, and proliferation. Other reported health benefits include antioxidant, anti-inflammatory, and immunomodulatory activities. Our current understanding is that graviola components modulate several cellular processes including inhibition of signaling pathways downstream of the epidermal growth factor receptor (EGFR), with others causing downregulation of phosphatidylinositol-4,5-bisphosphate 3-kinase (PI3K/Akt), RAS, NF- $\kappa \mathrm{B}$, and JAK/STAT [31]. Further actions include inhibition of HIF-1 $\alpha$, GLUT1, and GLUT4 [28]; proinflammatory cytokine expression (inflammation); and generation of reactive oxygen species (ROS) via upregulatoin of enzyme systems like catalase (CAT), superoxide dismutase (SOD), and heme-oxygenase (HO-1) expression $[39,54,89,124]$.

fruit extracts induce toxicity only against both breast T47D [22] and lung H-460 [95] cancer cells. In addition, while ethanolic twig extract shows cytotoxic activity against ECV-304 cancer cells in vitro [96], methanolic extracts of the leaves, pericarp, or seeds of $A$. muricata all exert toxicity against glioma U87MG, breast MDA-MB-231-pcDNA3 and MDA-MB-231-BCRP clone 23, colorectal HCT-116 $\left(p 53^{+/+}\right)$, and HCT-116 $\left(p 53^{-/-}\right)$cancer cells [24]. Moreover, stem methanolic extract induces cytotoxicity towards leukemia U-937 cells [33].

\section{Apoptosis}

Apoptosis, or programmed cell death, is integral for normal development and tissue homeostasis in most multicellular organisms [99]. Apoptosis plays a vital role in destroying cells which are selectively unnecessary or that present a threat to the integrity of an organism, thereby limiting the development and/or spread of cancer [1]. In many cancers, however, the gene(s) regulating apoptosis are faulty which leads to uncontrolled proliferation [100]. The ability to induce cellular apoptosis in tumor tissue is the key to finding a successful natural product as an anticancer agent $[27,101]$.

Apoptosis displays characteristic morphological and biochemical changes which may include cell shrinkage, nuclear fragmentation, chromatin condensation, and membrane blebbing [99, 102, 103]. The major apoptotic pathways are intrinsic and extrinsic [104]. The intrinsic (or mitochondrial) pathway can be induced through intracellular stresses such as DNA damage or oxidative stress leading to the release of mitochondrial cytochrome c forming the apoptosome complex [105]. This complex is composed of cytochrome c, apoptotic protease activating factor, and procaspase [106], which activates different caspases [107]. The extrinsic pathway, also known as the death receptor pathway, can be induced by death ligands, tumor necrosis factor $\alpha$, and tumor necrosis factor-related apoptosis inducing 
ligand (TRAIL)) [108]. These ligands bind to their cell surface receptors (tumor necrosis factors), death receptors, and Fas causing sequential activation of caspase-8, caspase3 , and caspase-7 [109]. Moreover, apoptosis is regulated by several proteins such as BCL-2 [110], BAX [111], and PCNA [25].

Several studies examining the anticancerous properties in A. muricata extracts have observed the induction of apoptosis. According to the available data, there are about six extract types with regard to solvent extraction of $A$. muricata parts, including water [21], ethanol [20, 112], methanol, ethyl acetate [31], chloroform, and n-hexane [37] extracts. Leaf extracts of $A$. muricata induce apoptosis in breast MDAMB-468 cancer cells through caspase-3 activation [23]. Similarly, A. muricata fruit extract induces apoptosis in breast T47D cancer cells [22]. An ethanolic extract of A. muricata leaves induces apoptosis [20] in COLO-205 colon cancer cells through upregulation of proapoptotic caspase-3 marker activity [112]. Similarly, in HT-29 colorectal cancer cells, annomuricin $\mathrm{E}$ derived from leaves of $A$. muricata induced apoptosis mediated through activation of caspases $3 / 7$ and 9, upregulation of BAX, and downregulation of BCL-2 at the mRNA and protein levels [25]. In K562 leukemia cancer cells, an ethanolic leaf extract significantly enhanced caspase3 activity to induce apoptosis, which was confirmed by a terminal deoxynucleotidyl transferase-mediated dUTP nick-end labelling (TUNEL) assay [19]. In addition, ethanolic extracts of roots, fruits, or leaves of $A$. muricata have been shown to induce apoptosis in HL-60 leukemia cancer cells through loss of MMP [27]. An aqueous leaf extract was shown to reduce prostate size which was suggested to have been due to apoptosis [21]. Leaf extracts prepared using various solvents were also able to induce apoptosis on HeLa cervical cancer cells [37]. Treatment of colorectal HT-29 and HCT-116 cancer cells with an ethyl acetate extract of leaves caused apoptosis through excessive accumulation of ROS followed by disruption of MMP, cytochrome c leakage, activation of the initiator and executioner caspases, upregulation of Bax, and downregulation of Bcl-2 protein [25]. An ethyl acetate leaf extract also elicited a $72.5 \%$ reduction in aberrant crypt foci inhibition in azoxymethane-induced colorectal carcinogenesis in rats [25]. This effect was associated with a downregulation of PCNA and $\mathrm{Bcl}-2$ proteins and an upregulation of Bax protein as well as an increase in the levels of enzymatic antioxidants and a decrease in the malondialdehyde level of the colon tissue homogenates suggesting the suppression of lipid peroxidation [25]. Similarly, an ethyl acetate extract derived from leaves of $A$. muricata induced apoptosis in lung A549 cancer cells through elevating ROS formation, followed by attenuation of MMP via upregulation of Bax and downregulation of Bcl-2. These effects were accompanied by the release of cytochrome $\mathrm{c}$ into the cytosol, which triggered the activation of caspase- 9 followed by caspase- 3 activation. Moreover, the treatment also suppressed the induced translocation of NF- $\kappa \mathrm{B}$ from cytoplasm to nucleus [31]. Apoptosis also has been shown in HeLa cervical cancer cells after treatment with an ethyl acetate leaf extract [37]. Methanolic extracts of seeds or leaves were also shown to induce apoptosis in leukemic
CCRF-CEM cells, while pericarp or leaf extracts induced apoptosis in CEM/ADR5000 leukemia cells [24]. Furthermore, leaf extracts using ethyl acetate and ethanol-distillate water, as well as $n$-hexane and chloroform leaf extracts, have also been shown to induce apoptosis in HeLa cervical cancer cells [37].

\section{Modulation of Cellular Proliferation}

Proliferation is a hallmark of cancer development and progression manifested by altered expression and/or activity of cell cycle-related proteins. In cancer, the normal cell cycle process is impaired, resulting in uncontrolled cell proliferation, growth, and tumor progression A. muricata extracts, and AGEs have been shown to regulate the cell cycle machinery, leading to cell cycle arrest and inhibition of cell proliferation. According to the available data, there are about seven AGEs and five extracts which have demonstrated antiproliferative activity. Specific AGEs include muricins J, K, L [29], $\mathrm{M}$, and N; muricenin [30]; and annomuricin E [25]. Extracts with antiproliferative properties include those using solvents such as hexane [30], ethyl acetate [77], methanol [113], ethanol [27], and water [91] as discussed below.

Muricins J, K or L, M, and N and muricenin leaf AGEs all have shown antiproliferative activities when tested on human prostate PC-3 cancer cells [29, 30]. Annomuricin E derived from leaves of $A$. muricata was reported to suppress proliferation of HT-29 colorectal cancer cells via cell cycle arrest at the G1 phase, which also induces leakage of lactate dehydrogenase [25].

Hexane, ethyl acetate, and methanol extracts all significantly reduced cell proliferation in hepatic Hep G2 and breast MCF-7 and MDA-MB-231 cancer cells [4]. A hexane leaf extract significantly reduced cell proliferation in PC-3 colorectal cancer cells [30]. Hexane and methanol extracts of A. muricata suppressed the proliferation of HT-29 and HCT-116 colorectal adenocarcinoma cells [26] as well as A549 [4] lung cancer cells. Antiproliferative and cytotoxic activities were seen in NCI-H292 cancer lung cells after treatment with methanol pericarp extract [113]. Ethanol extracts of roots, fruits, or leaves inhibited proliferation via G0/G1 cell cycle arrest in leukemia HL-60 cancer cells [26]. Hexane or DMSO seed extracts inhibited cell proliferation in pancreatic cancer Capan-1 cells [92]. An aqueous leaf extract showed promising antiproliferative activity by arresting the cell cycle in the G2M phase in SCC-25 squamous cell carcinoma [91]. A methanol leaf extract inhibited proliferation of Hep-2 cancer cells, first reported as laryngeal cancer cell line [113], currently authenticated as a cross-contaminated HeLa cell line [90] (http://iclac.org/ databases/cross-contaminations). Finally, A. muricata leaf extracts were reported to induce cell cycle arrest at the G0/ G1 phase in MDA-MB-468 breast [23], HCT-116 [31], and HT-29 [25] colorectal and A549 [31] lung cancer cells, and our preliminary unpublished observations showed similar effects on two nonmelanoma skin cancer cell lines, namely a basal (UWBCC1) and a squamous (A431) carcinoma cell line [116]. 


\section{Necrosis and Other Related Effects}

The death of cells in a tissue due to chemotherapeutic agents is defined as "necrosis" which contributes to chemotherapy-induced cell death [115]. Necrotic cell death is distinguished from its counterpart, apoptosis, in that caspase activation is not required for cell death. Unlike apoptosis, chemotherapy-induced necrosis results in plasma membrane rupture, thus spilling the contents of the cell and triggering the immune system. This results in the inhibition of cellular metabolism and induces further necrosis through the downregulation of factors related to hypoxia and glycolysis (i.e., HIF- $1 \alpha$, NF- $\kappa$ B, GLUT1, GLUT4, HKII, and LDHA) in pancreatic FG/COLO357 and CD18/HPAF cancer cells [28].

Cancer cell motility, migration, and invasion also play fundamental roles in cancer metastasis [116]. Therefore, inhibiting either cancer cell motility, migration, or invasion impedes metastasis, which is the cause of over $90 \%$ of patient deaths [117]. After treatment of pancreatic FG/COLO357 and CD18/HPAF cancer cells with leaf extracts, the motility of cancer cells was decreased [28]. More dramatically, treatment of HT-29 and HCT-116 colorectal cancer cells with an ethyl acetate leaf extract conspicuously blocked the migration and invasion of cancer cells $[25,26]$. In addition to the preclinical studies with cell lines cited above, a subset of these effects have been demonstrated in a clinical model system [118].

\section{Other Potential Health-Related Benefits}

In addition to cancer chemopreventive and chemotherapeutic effects, graviola extracts and their constituents, individually or in combination, have shown therapeutic properties for other ailments that afflict humankind including chronic inflammatory and oxidative diseases, wounds, and noninfectious and infectious microbial and parasitic diseases. Graviola organs have been used as herbal medications against cystitis, diabetes, headaches, hypertension, insomnia, and liver diseases as well as antidysenteric, anti-inflammatory, and antispasmodic agents [119]. Other benefits thus far reported for graviola constituents, in addition to those listed above, have included anxiolytic, anticancer, antitumorigenic, antidepressant, gastroprotective, antimalarial, antinociceptive, immunomodulatory, antistress, and wound healing activities $[4,120]$, some of which are reviewed below.

\section{Anti-inflammatory, Antinociceptive, Antiarthritic, Immunomodulatory, and Wound Healing Activities}

Over the last few decades, herbal remedies and natural phytochemicals have garnered scientific interest for their utility in managing pain and inflammation. Natural agents including $A$. muricata can mechanistically modulate these effects by impacting molecular targets, some of which are common to pain medications such as NSAIDs, but with reduced side effects. The following examples from the literature are provided.
An ethanol extract of graviola leaves was administered orally to rats by de Sousa et al., followed by various tests of nociception and inflammation [119]. These authors found the following dose-dependent effects: (a) reduction in abdominal contortions after ip injection of acetic acid, (b) increased time to paw licking after subplantar injections of $2.5 \%$ formalin, (c) increased reaction time in a hot plate test, (d) reduced edema after subplantar injection of $2 \%$ carrageenan, and (d) reduced exudate and leucocyte counts after carrageenan-induced pleurisy. Taken together, these observations were interpreted by the authors as a confirmation of the ethnomedical use of ethanol extracts of graviola leaves for therapeutic purposes. However, one caution was that the ethanol extract was toxic to animals at approximately $1.7 \mathrm{~g} / \mathrm{kg}$, leading the authors to call for further studies to ensure safe usage in humans.

Similar tests with an ethanol extract of graviola leaves were carried out by [121], who confirmed the antinociceptive properties of this extract. These authors extended these studies to include an ethanol-induced ulcer model in rats pretreated with N-nitro-L-arginine methyl ester (L-NAME), finding that the graviola extract dose-dependently reduced the size of the ulcerative lesions. This effect was inhibited by $\mathrm{N}$-ethylmaleimide, prompting the authors to conclude that the protective effect of the graviola extract in this setting might be due, at least in part, to antioxidant properties that increase the sulfhydryl content of the gastric mucosa [121].

Hamid et al. also tested an ethanol extract of graviola leaves, administered orally to rodents, for its acute and chronic anti-inflammatory actions. These authors reported that the ethanol extract (a) reduced xylene-induced ear edema in mice, (b) attenuated arthritis in rats induced by complete Freund's adjuvant, and (c) reduced TNF- $\alpha$ and IL- $1 \beta$ levels in the arthritis model, suggesting that the antiarthritic actions are at least partially due to a suppression of proinflammatory cytokines.

Ishola et al. used methodology similar to that described above (writhing, formalin, hot plate tests, carrageenaninduced rat paw edema, and xylene-induced ear edema tests) to test lyophilized fruit extracts of graviola [122]. These authors also found a dose-dependent inhibition of (a) writhes, (b) formalin-induced pain, (c) carrageenaninduced paw circumference, and (d) xylene-induced ear edema. This study also probed the possible involvement of the opiodergic, nitric oxide, and prostaglandin pathways, with the following results: (a) the anti-inflammatory actions of the fruit extracts were blocked by NG-nitro-L-arginine (a nitric oxide inhibitor) as well as by naloxone and (b) treatment with extract dose-dependently inhibited both COX-1 and COX-2. These authors therefore concluded that the analgesic and anti-inflammatory actions of a graviola fruit extract, as it is used in traditional African medicine, are confirmed and that these actions involve the opiodergic, prostaglandin, and nitric oxide systems [122].

Laksmitawati et al. tested an ethanol extract of graviola leaves in cultures of the LPS-stimulated murine macrophage cell line (RAW264.7) [123] and performed cell viability, cytokine ELISAs, and nitric oxide (NO) production assays. These authors reported that (a) cell viability was not affected 
in doses up to $50 \mu \mathrm{g} / \mathrm{mL}$ and b) levels of TNF- $\alpha$, IL- $1 \beta$, IL-6, and $\mathrm{NO}$ were all reduced relative to untreated cells.

Oliveira et al. used an aqueous extract of graviola in a similar in vitro study of inflammatory markers using RAW264.7 cells along with cell-free assays in comparison with an aqueous extract from Jasminum grandiflorium [67]. In addition to examining $\mathrm{NO}$ production, these authors also performed HPLC with diode array detection (HPLC-DAD) to determine the phenolic compounds responsible for some of the effects. These authors reported that (a) graviola was superior to J. grandiflorium in inhibiting both NO production as well as phospholipase $\mathrm{A}_{2}\left(\mathrm{PLA}_{2}\right)$ and (b) aglycones from the extract especially quercetin and 5-O-caffeoylquinic acid were capable of inhibiting NO production and/or $\mathrm{PLA}_{2}$ in low micromolar concentrations. Cytotoxicity was not noted at the concentrations tested in this study [67].

Related to graviola's anti-inflammatory effects are its ability to promote wound healing; indeed, graviola preparations are commonly used in folk medicine for skin diseases and abscesses. Moghadamtousi et al. used an ethyl acetate extract of graviola leaves in an excisional wound rat model [4]. In addition to examining antioxidant activity of this extract (see discussion above), these authors also performed histological and immunohistochemical analysis of wounds treated with ointments containing the extract using intrasite gel as a positive control. Their results showed that (a) both doses of extract showed significant acceleration of wound closure and tissue regeneration, with the higher dose being comparable to the intrasite positive control, and (b) both doses of extract upregulated heat shock protein 70 (Hsp70) to levels comparable to those seen in the intrasite-positive control as monitored by immunohistochemical staining. These authors concluded that there is a clear wound healing effect of the extract, even though the bioactive compounds responsible for the effect have not yet been identified [4].

\section{Antioxidant Activity}

Several reports have described the antioxidant properties of various graviola-derived extracts. These will be described in order of appearance in the literature.

Given that graviola leaves are used in Cameroon to manage diabetes, Florence et al. tested an aqueous extract of graviola leaves in streptozotocin-induced diabetic rats [54]. Although this extract had no effect on normal rats, the aqueous extract was found to reduce blood glucose levels in diabetic rats. These authors also found the following: (a) after 15 days of treatment with $100 \mathrm{mg} / \mathrm{kg}$ of extract (given 3 days prior to streptozotocin), animals showed significant (46\%) reductions in blood glucose compared to diabetic controls not treated with extract, (b) immunostaining at the end of treatment showed preservation of pancreatic $\beta$-cells in treated animals compared to diabetic controls not treated with extract, (c) activity of superoxide dismutase (SOD) and catalase in diabetic animals treated with extract $(100 \mathrm{mg} / \mathrm{kg})$ were normalized up to levels seen in nondiabetic controls, and (d) levels of tissue malondialdehyde (a marker of lipid peroxidation) and nitrites were reduced down to levels seen in nondiabetic animals. These studies in rats support the use of graviola as an antidiabetic agent and suggest that at least part of its beneficial actions are antioxidant in nature. One cautionary observation was made, however: a higher dose $(200 \mathrm{mg} / \mathrm{kg})$ of extract was not only less effective but also resulted in $25 \%$ mortality among that treatment group [54].

Gavamukulya et al. tested the antioxidant potential of ethanolic and aqueous extracts of graviola found in Eastern Uganda using 2,2-diphenyl-2-picrylhydrazyl (DPPH•) and reducing power assays [93]. Their results indicated that (a) the ethanolic extract was superior to the aqueous extract with respect to both reducing power and in vitro antioxidant activity and (b) the ethanolic extract, but not the aqueous extract, was selectively cytotoxic to three tumor cell lines as opposed to no effect on normal spleen cells [93].

George et al. compared methanolic and aqueous extracts of graviola with respect to their free radical scavenging and DNA protective properties using several assays including a ferric reducing antioxidant property (FRAP) assay, a DPPH• radical scavenging assay, a hydroxyl scavenging activity assay (HRSA), and a DNA damage protective activity [124]. These authors also carried out HPLC analysis of phenolic compounds in each extract. Both graviola extracts were found to possess significant radical scavenging assays, and a strong positive correlation was seen between the total phenolic content and the radical scavenging activity of each extract. The methanolic extract was found to confer superior protection against hydrogen peroxide-induced DNA damage [124].

Moghadamtousi et al. applied an ethyl acetate extract of graviola leaves to skin wounds in rats [4]. Although wound healing was the main focus of this study (see above), these authors also measured levels of malondialdehyde as well as activities of catalase, glutathione peroxidase, and superoxide dismutase in wound tissue homogenates. After 15 days of treatment, analysis of tissue samples revealed a "significant surge in antioxidants activities and decrease in the MDA level of wound tissues compared with vehicle control," providing yet another example of the antioxidative potential of graviola extracts [124].

Finally, Son et al. studied the antioxidant properties of steam and 50\% ethanol extracts of graviola leaves in HepG2 cells [125]. Their results, standardized in some cases to vitamin $\mathrm{C}$ equivalents, indicated that (a) the 50\% ethanol extracts were superior than steam extracts in scavenging peroxy and nitrogen radicals, although both were effective, and (b) the $50 \%$ ethanol extract upregulated superoxide dismutase 1 (SOD1) and Nrf2 (an important transcriptional regulator of antioxidant enzymes), but not catalase or heme oxygenase 1 (HMOX1).

In summary, accumulating evidence suggests that components of graviola possess potent antioxidant properties, although these may vary depending on the method of extraction as well as the cells/tissues in which they are tested.

\section{Hepatoprotective Effects Related to Antioxidation}

As described above, Adewole and Ojewole observed hepatic benefits after administration of an aqueous leaf extract of 
graviola to streptozotocin-induced diabetic rats [39]. The described benefits in liver consisted mainly of increases in antioxidant enzymes (catalase, SOD, and glutathione peroxidase) and levels of glutathione to reduce oxidative stress in this tissue. However, other positive effects of this treatment included improvements in blood lipid levels, specifically a decline in diabetes-induced levels of LDL, total cholesterol, and triglycerides and an increase in HDL [39].

Padma et al. tested the ability of an ethanol extract of graviola stem bark, in comparison with a similar extract from Polyalthia cerasoides, to ameliorate carbon tetrachloride liver toxicity in albino rats [126], using liver function tests as a measure of liver damage. Their results showed that the graviola extract was superior to the $P$. cerasoides extract in (a) reducing blood levels of liver transaminases (ALT/SGPT and AST/SGOT) and alkaline phosphatase released into the blood by the liver damage and (b) reducing lipid peroxidation in liver samples as measured by detection of MDA. While the protection of liver was not complete, the reduction in these measures of liver damage by graviola (but not by $P$. cerasoides $)$ was highly significant $(P<0.001)$ in each case when compared to controls (number of animals in each group ranged from 7 to 10 ).

\section{Antidiabetic and Hypotensive Properties}

As already mentioned, graviola extracts have been used as antidiabetic agents in many parts of the world (see [127] above). Additional evidence for the presence of antidiabetic agents in graviola extracts has been reported as follows.

Adewole and Ojewole administered an aqueous leaf extract of graviola to streptozotocin-induced diabetic rats [39]. After four weeks of treatment, these researchers found that (a) glucose levels were reduced in treated diabetic rats along with an elevation in blood insulin, (b) levels of ROS and blood lipids also declined in treated diabetic rats, and (c) activities of antioxidant enzymes (catalase, SOD, and glutathione peroxidase) and levels of glutathione were increased in liver relative to untreated diabetic animals. This study mainly focused on the hepatic benefits of graviola treatment in the setting of diabetes, with the conclusion that graviola is protective against oxidative stress in this tissue.

In addition to antidiabetic properties of graviola (Annona muricata), it should also be noted that a closely related plant, Annona montana (also known as "false graviola"), has been tested for its effect on blood lipids and blood glucose. Treatment of Wistar rats for 40 days with juices prepared from either leaf or fruit not only showed reduced blood glucose and blood low-density lipoproteins but also increased levels of high-density lipoproteins, prompting these authors to propose that use of this plant may help prevent diabetes mellitus and dyslipidemia [128].

Finally, Nwokocha et al. administered an aqueous leaf extract by IV injection to normotensive Sprague-Dawley rats, and short-term measurements (10 minutes apart) were taken of systolic and diastolic blood pressure, after which animals were sacrificed and aortic rings were isolated and tested in an isometric force transducer system [12]. These authors reported that (a) both systolic and diastolic blood pressures were reduced in a dose-dependent manner by the graviola extract, but without an effect on heart rate; (b) further tests determined that these effects were apparently not due to muscarinic, endothelial, histaminergic, or adrenergic mechanisms; and (c) testing of aortic rings suggested that alkaloid components of the extract might be exerting these effects via blockade of calcium ion channels, speculating that reticuline, an alkaloid found in graviola leaves [129], might be contributing to these effects [12].

\section{Antimicrobial and Antiparasitic Potentials}

Graviola parts have been used as antimicrobial and antiparasitic agents in traditional medicine. Examples are provided according to the year published, except for antimalarials which will be discussed at the end of this section.

Bories et al. studied methanol extracts of two species of Annona, including muricata (graviola) and cherimolia, for their ability to inhibit growth of the parasites Entamoeba histolytica, Trichomonas vaginalis, Nippostrongylus brasiliensis, Molinema dessetae, and Artemia salina [130]. Results were expressed in terms of minimum inhibitory concentration (MIC), compared to reference compounds metronidazole (for E. histolytica) and ivermectin (for N. brasiliensis and $M$. dessetae). The results with crude extracts showed that (a) the A. cherimolia extract performed better overall in these tests and (b) both extracts showed only weak activity against the protozoans E. histolytica and T. vaginalis but strongly inhibited the $M$. dessetae filaria larvae, although at doses still an order of magnitude or so higher than the reference ivermectin compound. Nevertheless, this last result prompted the authors to perform fractionation to identify compounds with effectiveness against $M$. dessetae, leading to the identification of seven acetogenins with filaricidal activity, four of which displayed $\mathrm{LD}_{50}$ values equal to or lower than the ivermectin reference [130].

Osorio et al. compared 36 different extracts from six different plants, including six extracts from graviola, namely, hexane, ethyl acetate, and methanol extracts from stem and from leaves, for their effects on three Leishmania species, as well as on Trypanosoma cruzi and Plasmodium falciparum [131]. Briefly summarized, an ethyl acetate extract of graviola leaves and stems was found to have potent activity against Leishmania, but the relatively high toxicity displayed by the leaf extract in cultures of U-937 cells led the authors to conclude that the effectiveness against the Leishmania parasite likely reflected its toxicity against the host mammalian cells [131].

Vila-Nova et al. tested specific compounds from both graviola and Platymiscium floribundum for their effectiveness against three Leishmania species (donovani, mexicana, and major) [132]. The most potent leishmanicidal compound against all three species was the acetogenin annonacinone $\left(\mathrm{EC}_{50}\right.$ approximately $\left.7 \mu \mathrm{g} / \mathrm{mL}\right)$, although corossolone and the coumarin scoparone (the latter compound from $P$. floribundum) also displayed moderate activity, suggesting that these compounds merit further development for treatment of leishmaniasis [132]. 
Mathew et al. examined aqueous extracts of leaves from graviola and Simarouba glauca on the dental root canal pathogen Enterococcus faecalis [133]. These authors reported that the graviola extract, but not the S. glauca extract, was as effective against $E$. faecalis in vitro as the sodium hypochlorite ( $1 \%$ bleach) reference disinfectant, providing a possible alternative for root canal irrigation.

Mithun Pai et al. similarly tested an aqueous extract of graviola leaves against the oral pathogens Streptococcus mutans, Streptococcus mitis, Porphyromonas gingivalis, Prevotella intermedia, and Candida albicans using an agar disc method [66]. Their results showed that (a) graviola displayed effectiveness against all organisms except for $P$. intermedia, with the highest dose being the most effective and a trend toward dose dependence, and (b) compared to the "gold standard controls" of ciprofloxacin for the bacteria and fluconazole for the Candida yeast, the graviola extracts were far less effective, but may warrant further testing especially in view of (to paraphrase the authors) their combined antimicrobial and (reputed) anticancer effects [66].

Simo et al. prepared ethanol extracts of leaves, stems, and roots from several plants belonging to the Annonaceae family, including graviola, and tested them for phenolic and flavonoid content, as well as antioxidant and antifungal activities, using various strains of Candida yeast and Cryptococcus neoformans [134]. Briefly summarizing the results, these authors showed that (a) all three extracts from graviola possessed free radical-scavenging activity (root being highest) and (b) all three compounds showed "moderate" antifungal activity (approximately two orders of magnitude less potent on a $\mathrm{mg} / \mathrm{mL}$ basis as compared with a nystatin control).

Several studies have investigated the ability of extracts from plants, including graviola, to treat malaria caused by Plasmodium falciparum, with particular interest in chloroquine-resistant strains of this organism. Ménan et al. prepared aqueous, ethanol, and pentane extracts of 18 plants used in traditional medicine, including graviola leaves, and tested these in culture against two African strains of $P$. falciparum, one sensitive to chloroquine and the other resistant to the drug, to determine $\mathrm{IC}_{50}$ values (defined as concentrations required to inhibit $P$. falciparum growth in human blood cell culture by 50\%) [36]. These authors also tested cytotoxicity of each extract on A375 melanoma cells, using incorporation of radiolabeled hypoxanthine as a measure of cell growth. Their results showed that (a) $\mathrm{IC}_{50}$ values in most cases were highest for the pentane extracts, with the graviola pentane extract showing not only "excellent" antiplasmodial activity but also a favorable ratio of antiplasmodial to cytotoxicity activity (ratio greater than 10), (b) activity against the chloroquine-resistant strain was just as good, if not better, than activity against the chloroquine-sensitive strain, and (c) in contrast to the antiplasmodial activities, the cytotoxic effects were greatest with the ethanol extract (6-7 fold lower $\mathrm{IC}_{50}$ compared with the pentane extract; the aqueous extract was largely ineffective in this assay). It should be noted that extracts from Uvaria afzelii and Cola caricaefolia also displayed significant antiplasmodial activities [36].
Mohd Abd Razak et al. tested the antiplasmodial activity of 54 extracts from 14 medicinal plant species using an ELISA assay for P. falciparum histidine-rich protein; cytotoxicity was evaluated in Madin-Darby bovine kidney (MDBK) cells using an MTT assay [135]. These authors reported that 11 of these extracts possessed antiplasmodial activities with "negligible" toxicity (ratio of antiplasmodial to cytotoxicity activity greater than 10). Specific findings for graviola were that all three leaf extracts tested (aqueous, methanol, and dichloromethane) displayed "promising" EC50 values of between 0.1 and $1 \mu \mathrm{g} / \mathrm{mL}$ combined with low toxicity to MDBK cells, with a ratio of antiplasmodial to cytotoxicity activity of $>750$ for the aqueous extract [135].

Somsak et al. also tested an aqueous leaf extract from graviola for its antiplasmodial activity and acute toxicity using an in vivo, Plasmodium berghei-infected mouse model [13]. To test for antimalarial action, mice were injected ip with parasitized erythrocytes, followed by four consecutive days of oral treatment with $100-1000 \mathrm{mg} / \mathrm{kg}$ of extract, using chloroquine as a positive control. The results indicated a significant and dose-dependent inhibition of parasitemia (up to over $85 \%$ at the highest dose), along with prolonged survival from 7 days in untreated mice up to almost 29 days in mice treated with the highest dose, almost equaling the effectiveness of chloroquine (99\% inhibition of parasitemia and 30-day survival). Toxicity studies showed no mortality doses up to $4000 \mathrm{mg} / \mathrm{kg}$. The authors concluded that graviola extracts could potentially be the basis for the development of safe, effective, and affordable antimalarial agents [13].

Yamthe et al. tested a series of extractions and subfractions from both A. muricata (graviola) and the related $A$. reticulata for their activity against $P$. falciparum (strain W2 in culture) as well as cytotoxicity against human erythrocytes and foreskin fibroblasts [136]. Whereas all extracts showed low toxicity and some ability to inhibit growth of $P$. falciparum, thus supporting traditional use of these plants against malaria, the most potent extract was found by these authors to be a column chromatography subfraction from a methylene chloride stem bark extract of graviola, which displayed and $\mathrm{IC}_{50}$ of $70 \mathrm{ng} / \mathrm{mL}$, with a ratio of antiplasmodial to cytotoxicity activity of $>140$. The authors planned to continue characterizing active subfractions and individual compounds to improve antiplasmodial activity and minimize cytotoxicity [136].

\section{Toxicological and Safety Information}

As briefly discussed above, several studies have included cytotoxic assays and other means of assessing toxicity in their studies of graviola extracts. The following comments are intended to provide perspective into the possibility of toxicity in the use of graviola components. Caparros-Lefebvre and Elbaz in 1999 reported that consumption of teas and fruits of some tropical plants, including graviola, was associated with atypical parkinsonism, leading to speculation that graviola might contain neurotoxins reviewed by Gavamukulya et al. [120]. No safety studies have been found to assess the efficacy of the extracts of A. muricata on the various cancers. A study discussed the possible connection between tropical 
fruit intake and the occurrence of atypical parkinsonism in the French West Indies [4, 120]. Another study in Guadeloupe Island publicized an association between intake of AGEs and the endemicity of a neurodegenerative disease [137], suggesting that AGEs are environmental neurotoxins accountable for neurodegenerative disorders. One of several follow-up studies focused on one of the AGE compounds, namely, annonacin, in causing tau-related neuropathology [137]. However, a consensus was reached in 2010 that consumption of species of Annonaceae was not directly related to occurrence of atypical parkinsonism (reviewed in $[4,120])$. Other toxicologic findings discussed above in relation to the individual studies nevertheless merit serious consideration such that future studies of the use of graviola components must include rigorous safety testing since the content of potential toxins could vary according to the part of the plant, the extraction method, the location where the plant is grown, and even the time of harvest. Employing mesencephalic dopaminergic neurons, rat striatal neuronal cells, and laboratory rats, the neurotoxicity of seven acetogenins was evaluated, and the most abundant acetogenin (annonacin) and alkaloid (reticuline) from A. muricata were demonstrated to be neurotoxic [4]. Annonacin is a thousand times $(1000 x)$ more toxic to cultured neuronal cells than reticuline and a hundred times $(100 \mathrm{x})$ more potent than 1-methyl4-phenylpyridinium, a known neurotoxin that effects parkinsonism in humans and animal models. Intravenous administration of isolated annonacin to laboratory rats was determined to estimate the amount of annonacin a human should consume via the ingestion of fruit daily for one year. In this regard, AVIS (l'Agence Francaise de Sécurité des Aliments) issued a conclusive statement that based on available data, it is not possible to link atypical parkinsonian syndrome cases identified in Guadeloupe to consumption of plan species belonging to the Annonaceae family (reviewed in [4]).

\section{Conclusion and Future Prospects}

Despite enhanced synthetic small molecule-based targeted anticancer therapies with improved patient prognosis, cancer remains a leading cause of death worldwide, as a result of challenges including increased toxicity and development of resistance to treatment agents. Natural products found in medicinal plants have great promise for the treatment of cancer [71]. This current review demonstrates Annona murica$t a$ 's anticancer potential and other health-related benefits by providing insights into its bioactive chemical constituents as well as the in vitro and in vivo studies that have been carried out in order to elucidate the molecular mechanisms of action of these constituents. Graviola not only is a soughtafter tropical tree plant as an important foundation for the food industry and alternative traditional medicine but is also endowed with a wealth of phytochemicals with a wide variety of biological activities including its most prominent anticancer, antioxidant, and other properties not limited to those discussed herein.

Acetogenins and other secondary metabolites, including alkaloids, of this plant possess demonstrable ability to decrease growth of cancer that could be further comprehensively exploited. Acetogenins or other A. muricata-derived compounds could be tested as monotherapy or as sensitizers in combination with standard cancer treatments for cancer patients. Numerous studies have reported anticancer actions of A. muricata. However, more rigorous evaluation of various plant parts, their extracts, and ultimately isolated bioactive compounds is clearly warranted. Indeed, the most effective bioactive compounds from A. muricata could potentially serve as scaffold entities for design and synthesis of derivatives that may even be more efficacious in preclinical and clinical trials. Whereas earlier studies characterized the biological activities of extracts from different graviola organs, future studies pivotal for the development of pharmaceutical and agricultural product development should focus on investigating on the biochemical and physiological functions of active phytochemical compounds and their combinations, as well as the detailed molecular mechanisms causal to these activities, progressing from in vitro studies to in vivo rodent models and ultimately to clinical trials to assess safety as well as therapeutic efficacy of the most promising graviola components.

There is already one clinical case report which describes a 66-year-old female who was diagnosed with metastatic breast cancer and whose metastases had progressed even after multiple rounds of chemotherapy including anthracyclines and taxanes. This patient self-medicated by boiling 10-12 dry leaves of $A$. muricata in water for 5-7 minutes, then orally consumed an $8 \mathrm{oz}$ daily dose of this aqueous extract. Her metastases remained stable for 5 years on graviola (together with Xeloda) [118]. This report, although anecdotal, hints of the untapped antimetastatic potential of A. muricata and its components.

In a rodent in vivo study, graviola leaf extract inhibited $59.8 \%$ of pancreatic cancer growth of cells and their metastasis induced by CD18/HPAF cells in a mouse model [28].

In order to exploit the full medicinal potential of $A$. muricata, existing gaps in our knowledge of annonaceous acetogenins and other bioactive compounds should be addressed. Currently, there are no target-based approaches for evaluating components derived from A. muricata in cancer therapy. With the rapidly expanding knowledge of the pathways and networks that control cell signaling, proliferation, metastasis, and cell death, the possibility of using these components in a targeted fashion is very appealing in order to expand our anticancer armamentarium. Numerous in vitro and preclinical in vivo studies have supported most of the traditionally acclaimed benefits, but these must be validated in human clinical trials. The more than 200 phytochemicals identified in graviola mainly including acetogenins, alkaloids, and phenols have shown a multitude of pharmacological activities as discussed herein, and it is hoped that future studies will identify novel phytochemical scaffolding entities which are yet to be identified from A. muricata.

While most have provided health benefits, some of the derived phytochemicals like acetogenins have demonstrated in vitro and in vivo neurotoxicity. Although current consumption does necessarily lead to acute toxicity, further research to identify and quantify the amount of toxic 
phytochemicals as well as determine the doses to be exposed to humans to induce toxicity is urgently needed. For future directions and safety concerns in developing these plant aerial parts and their constituents, current studies indicate that phytochemical composition and anticancer properties vary with the geographical sources of A. muricata [58]. Because consistent results are difficult to achieve since processing and formulation may vary from the desired biological activity, there is therefore the need for systematic and robust screening to identify biochemical fractions as well as the physiological effects of all isolated constituents by detailing the investigation of underlying mechanisms. More importantly, for more safety, the toxicological profile is required to be documented $[137,138]$. Another area previously neglected that needs to be intensely focused on is clinical trials concerning the rich pharmaceutical potential of A. muricata.

In conclusion, the authors intended this review to be a call to action for the development of better graviolabased pharmaceutical, agricultural, and food industrial agents, for the human diseases and conditions discussed herein, and possibly for other conditions for which graviola components have not even been tested. Given that graviola is already widely used in traditional medicine, these agents, if properly tested and produced, could potentially represent huge benefit by providing accessible and affordable agents against many of the conditions that plague humankind.

\section{Disclosure}

Roxane-Cherille N. Chamcheu's current address is West Monroe High School, 201 Riggs Street, West Monroe, LA 71291, USA.

\section{Conflicts of Interest}

The authors declare that they have no conflict of interests.

\section{Authors' Contributions}

These authors, Islam Rady, Melissa B. Bloch, and RoxaneCherille N. Chamcheu contributed equally to this work. Islam Rady gathered the information and wrote the initial draft of the manuscript. Melissa B. Bloch, Roxane-Cherille N. Chamcheu, Sergette Banang Mbeumi, and Md Rafi Anwar gathered and contributed new information, added figures and tables, and restructured the first draft of the manuscript. Jean Christopher Chamcheu revised it for intellectual content and coordinated the study, as well as all other authors. All authors edited and reviewed the different versions of the manuscript and approved the final version for submission.

\section{Acknowledgments}

The authors thank Dr. Jean Fotie for providing the ChemDraw chemical structures of graviola constituent molecules herein and for editorial suggestions to this manuscript. Research work on graviola in Jean Christopher Chamcheu's laboratory is supported in part by a start-up funding from the University of Louisiana at Monroe School of Pharmacy and a College of Pharmacy Faculty Research Seed Grant (no. 5CALHN-260615) to Jean Christopher Chamcheu. Carson Research Scholar Award in Psoriasis from the American Skin Association (ASA) and a UW-Madison Skin Disease Research Center (SDRC) Pilot and Feasibility Research Award from NIH/NIAMS Grant P30 AR066524 are given to Jean Christopher Chamcheu. Research in Dr. El Sayed's laboratory is partly supported by a National Institutes of Health Grant R15CA16747 to Khalid A. El Sayed.

\section{References}

[1] I. Rady, I. A. Siddiqui, M. Rady, and H. Mukhtar, "Melittin, a major peptide component of bee venom, and its conjugates in cancer therapy," Cancer Letters, vol. 402, pp. 16-31, 2017.

[2] H. Frankish, " 15 million new cancer cases per year by 2020 , says WHO,” The Lancet, vol. 361, no. 9365, p. 1278, 2003.

[3] R. L. Siegel, K. D. Miller, and A. Jemal, "Cancer statistics, 2018," CA: A Cancer Journal for Clinicians, vol. 68, no. 1, pp. 7-30, 2018.

[4] S. Moghadamtousi, M. Fadaeinasab, S. Nikzad, G. Mohan, H. Ali, and H. Kadir, "Annona muricata (Annonaceae): a review of its traditional uses, isolated acetogenins and biological activities," International Journal of Molecular Sciences, vol. 16, no. 7, pp. 15625-15658, 2015.

[5] S. Nussbaumer, P. Bonnabry, J. L. Veuthey, and S. FleurySouverain, "Analysis of anticancer drugs: a review," Talanta, vol. 85, no. 5, pp. 2265-2289, 2011.

[6] B. Peter, S. Bosze, and R. Horvath, "Biophysical characteristics of proteins and living cells exposed to the green tea polyphenol epigallocatechin-3-gallate (EGCg): review of recent advances from molecular mechanisms to nanomedicine and clinical trials," European Biophysics Journal, vol. 46, no. 1, pp. 1-24, 2017.

[7] N. P. Gullett, A. R. M. Ruhul Amin, S. Bayraktar et al., "Cancer prevention with natural compounds," Seminars in Oncology, vol. 37, no. 3, pp. 258-281, 2010.

[8] U. P. de Albuquerque, G. T. Soldati, S. S. Sieber, M. A. Ramos, J. C. de Sá, and L. C. de Souza, "The use of plants in the medical system of the Fulni-ô people (NE Brazil): a perspective on age and gender," Journal of Ethnopharmacology, vol. 133, no. 2, pp. 866-873, 2011.

[9] E. E. Camargo, M. A. Bandeira, and A. G. de Oliveira, "Diagnosis of public programs focused on herbal medicines in Brazil," Natural Product Communications, vol. 6, no. 7, pp. 1001-1002, 2011.

[10] G. Komlaga, C. Agyare, R. A. Dickson et al., "Medicinal plants and finished marketed herbal products used in the treatment of malaria in the Ashanti region, Ghana," Journal of Ethnopharmacology, vol. 172, pp. 333-346, 2015.

[11] S. C. Gupta, J. H. Kim, S. Prasad, and B. B. Aggarwal, "Regulation of survival, proliferation, invasion, angiogenesis, and metastasis of tumor cells through modulation of inflammatory pathways by nutraceuticals," Cancer and Metastasis Reviews, vol. 29, no. 3, pp. 405-434, 2010.

[12] C. R. Nwokocha, D. U. Owu, A. Gordon et al., "Possible mechanisms of action of the hypotensive effect of Annona muricata (soursop) in normotensive Sprague-Dawley rats," Pharmaceutical Biology, vol. 50, no. 11, pp. 1436-1441, 2012. 
[13] V. Somsak, N. Polwiang, and S. Chachiyo, "In vivo antimalarial activity of Annona muricata leaf extract in mice infected with Plasmodium berghei," Journal of Pathogens, vol. 2016, Article ID 3264070, 5 pages, 2016.

[14] W. Z. Lee, S. K. Chang, H. E. Khoo, C. M. Sia, and H. S. Yim, "Influence of different extraction conditions on antioxidant properties of soursop peel," Acta Scientiarum Polonorum Technologia Alimentaria, vol. 15, no. 4, pp. 419-428, 2016.

[15] L. Zeng, F. E. Wu, Z. M. Gu, and J. L. McLaughlin, "Murihexocins $\mathrm{A}$ and $\mathrm{B}$, two novel mono-THF acetogenins with six hydroxyls, from Annona muricata (Annonaceae)," Tetrahedron Letters, vol. 36, no. 30, pp. 5291-5294, 1995.

[16] G. S. Kim, L. Zeng, F. Alali et al., "Two new monotetrahydrofuran ring acetogenins, annomuricin $\mathrm{E}$ and muricapentocin, from the leaves of Annona muricata," Journal of Natural Products, vol. 61, no. 4, pp. 432-436, 1998.

[17] F.-E. Wu, Z. M. Gu, L. Zeng et al., "Two new cytotoxic monotetrahydrofuran annonaceous acetogenins, annomuricins A and B, from the leaves of Annona muricata," Journal of Natural Products, vol. 58, no. 6, pp. 830-836, 1995.

[18] F.-E. Wu, L. Zeng, Z. M. Gu et al., "New bioactive monotetrahydrofuran annonaceous acetogenins, annomuricin $\mathrm{C}$ and muricatocin C, from the leaves of Annona muricata," Journal of Natural Products, vol. 58, no. 6, pp. 909-915, 1995.

[19] A. U. Ezirim, V. I. Okochi, A. B. James, O. A. Adebeshi, S. Ogunnowo, and O. B. Odeghe, "Induction of apoptosis in myelogenous leukemic k562 cells by ethanolic leaf extract of Annona muricata L," Global Journal of Research on Medicinal Plants \& Indigenous Medicine, vol. 2, no. 3, pp. 142-151, 2013.

[20] V. Eggadi, S. Gundamedi, S. B. B. Sheshagiri, S. K. Revoori, V. R. Jupally, and U. Kulandaivelu, "Evaluation of anticancer activity of Annona muricata in 1, 2-dimethyl hydrazine induced colon cancer," World Applied Sciences Journal, vol. 32, no. 3, pp. 444-450, 2014.

[21] G. A. Asare, D. Afriyie, R. A. Ngala et al., "Antiproliferative activity of aqueous leaf extract of Annona muricata L. on the prostate, $\mathrm{BPH}-1$ cells, and some target genes," Integrative Cancer Therapies, vol. 14, no. 1, pp. 65-74, 2014.

[22] E. P. N. Rachmani, T. S. Suhesti, R. Widiastuti, and A. Aditiyono, "The breast of anticancer from leaf extract of Annona muricata against cell line in T47D," International Journal of Applied Science and Technology, vol. 2, no. 1, pp. 198-2003, 2012.

[23] Y. Dai, S. Hogan, E. M. Schmelz, Y. H. Ju, C. Canning, and K. Zhou, "Selective growth inhibition of human breast cancer cells by graviola fruit extract in vitro and in vivo involving downregulation of EGFR expression," Nutrition and Cancer, vol. 63, no. 5, pp. 795-801, 2011.

[24] V. Kuete, J. K. Dzotam, I. K. Voukeng, A. G. Fankam, and T. Efferth, "Cytotoxicity of methanol extracts of Annona muricata, Passiflora edulis and nine other Cameroonian medicinal plants towards multi-factorial drug-resistant cancer cell lines," Springerplus, vol. 5, no. 1, article 1666, 2016.

[25] S. Zorofchian Moghadamtousi, E. Rouhollahi, H. Karimian et al., "The chemopotential effect of Annona muricata leaves against azoxymethane-induced colonic aberrant crypt foci in rats and the apoptotic effect of acetogenin annomuricin $\mathrm{E}$ in HT-29 cells: a bioassay-guided approach," PLoS One, vol. 10, no. 4, article e0122288, 2015.

[26] S. Zorofchian Moghadamtousi, H. Karimian, E. Rouhollahi, M. Paydar, M. Fadaeinasab, and H. Abdul Kadir, “Annona muricata leaves induce $G_{1}$ cell cycle arrest and apoptosis through mitochondria-mediated pathway in human HCT116 and HT-29 colon cancer cells," Journal of Ethnopharmacology, vol. 156, pp. 277-289, 2014.

[27] C. A. Pieme, S. G. Kumar, M. S. Dongmo et al., "Antiproliferative activity and induction of apoptosis by Annona muricata (Annonaceae) extract on human cancer cells," BMC Complementary and Alternative Medicine, vol. 14, no. 1, p. 516, 2014.

[28] M. P. Torres, S. Rachagani, V. Purohit et al., "Graviola: a novel promising natural-derived drug that inhibits tumorigenicity and metastasis of pancreatic cancer cells in vitro and in vivo through altering cell metabolism," Cancer Letters, vol. 323, no. 1, pp. 29-40, 2012.

[29] S. Sun, J. Liu, H. Kadouh, X. Sun, and K. Zhou, "Three new anti-proliferative Annonaceous acetogenins with monotetrahydrofuran ring from graviola fruit (Annona muricata)," Bioorganic \& Medicinal Chemistry Letters, vol. 24, no. 12, pp. 2773-2776, 2014.

[30] S. Sun, J. Liu, N. Zhou, W. Zhu, Q. P. Dou, and K. Zhou, "Isolation of three new annonaceous acetogenins from graviola fruit (Annona muricata) and their antiproliferation on human prostate cancer cell PC-3," Bioorganic \& Medicinal Chemistry Letters, vol. 26, no. 17, pp. 4382-4385, 2016.

[31] S. Z. Moghadamtousi, H. A. Kadir, M. Paydar, E. Rouhollahi, and H. Karimian, "Annona muricata leaves induced apoptosis in A549 cells through mitochondrial-mediated pathway and involvement of NF- $\kappa \mathrm{B}, " B M C$ Complementary and Alternative Medicine, vol. 14, no. 1, 2014.

[32] L. Zeng, F. E. Wu, N. H. Oberlies, J. L. McLaughlin, and S. Sastrodihadjo, "Five new monotetrahydrofuran ring acetogenins from the leaves of Annona muricata," Journal of Natural Products, vol. 59, no. 11, pp. 1035-1042, 1996.

[33] L. Valencia, D. L. Muñoz, S. M. Robledo et al., "Actividad tripanocida y citotóxica de extractos de plantas colombianas," Biomédica, vol. 31, no. 4, pp. 552-559, 2011.

[34] L. Zeng, F. E. Wu, and J. L. McLaughlin, "Annohexocin, a novel mono-THF acetogenin with six hydroxyls, from Annona muricata (Annonaceae)," Bioorganic \& Medicinal Chemistry Letters, vol. 5, no. 16, pp. 1865-1868, 1995.

[35] S. Hla Myint, D. Cortes, A. Laurens et al., "Solamin, a cytotoxic mono-tetrahydrofuranic $\gamma$-lactone acetogenin from Annona muricata seeds," Phytochemistry, vol. 30, no. 10, pp. 3335-3338, 1991.

[36] H. Ménan, J.-T. Banzouzi, A. Hocquette et al., “Antiplasmodial activity and cytotoxicity of plants used in West African traditional medicine for the treatment of malaria," Journal of Ethnopharmacology, vol. 105, no. 1-2, pp. 131136, 2006.

[37] O. P. Astirin, A. N. Artanti, M. S. Fitria, E. A. Perwitasari, and A. Prayitno, "Annonaa muricata linn leaf induce apoptosis in cancer cause virus," Journal of Cancer Therapy, vol. 4, no. 7, pp. 1244-1250, 2013.

[38] H. L. Ge, D. W. Zhang, L. Li et al., "Two new terpenoids from endophytic fungus Periconia sp. F-31," Chemical \& Pharmaceutical Bulletin, vol. 59, no. 12, pp. 1541-1544, 2011.

[39] S. Adewole and J. Ojewole, "Protective effects of Annona muricata linn. (Annonaceae) leaf aqueous extract on serum lipid profiles and oxidative stress in hepatocytes of streptozotocin-treated diabetic rats," African Journal of Traditional, Complementary and Alternative Medicines, vol. 6 , no. 1,2010 . 
[40] E. B. Ribeiro de Souza, R. R. da Silva, S. Afonso, and I. S. Scarminio, "Enhanced extraction yields and mobile phase separations by solvent mixtures for the analysis of metabolites in Annona muricata L. leaves," Journal of Separation Science, vol. 32, no. 23â24, pp. 4176-4185, 2009.

[41] A. V. Coria-Téllez, E. Montalvo-Gónzalez, E. M. Yahia, and E. N. Obledo-Vázquez, "Annona muricata: a comprehensive review on its traditional medicinal uses, phytochemicals, pharmacological activities, mechanisms of action and toxicity," Arabian Journal of Chemistry, vol. 30, 2016.

[42] A. C. Q. de Pinto, M. C. R. Cordeiro, S. R. M. de Andrade et al., "Annona muricata," in Annona Species, vol. 2005, Taxonomy and botany Inter-national Centre Underutilised Crops.

[43] F.-E. Wu, G. X. Zhao, L. Zeng et al., "Additional bioactive acetogenins, annomutacin and (2,4-trans and cis)-10R-annonacin-A-ones, from the leaves of Annona muricata," Journal of Natural Products, vol. 58, no. 9, pp. 1430-1437, 1995.

[44] F.-E. Wu, L. Zeng, Z. M. Gu et al., "Muricatocins A and B, two new bioactive monotetrahydrofuran Annonaceous acetogenins from the leaves of Annona muricata," Journal of Natural Products, vol. 58, no. 6, pp. 902-908, 1995.

[45] Á. I. Calderón, Y. Vázquez, P. N. Solís et al., "Screening of Latin American plants for cytotoxic activity," Pharmaceutical Biology, vol. 44, no. 2, pp. 130-140, 2006.

[46] M. C. Jaramillo, G. J. Arango, M. C. González, S. M. Robledo, and I. D. Velez, "Cytotoxicity and antileishmanial activity of Annona muricata pericarp," Fitoterapia, vol. 71, no. 2, pp. 183-186, 2000.

[47] G.-S. Kim, L. Zeng, F. Alali et al., "Muricoreacin and murihexocin $\mathrm{C}$, mono-tetrahydrofuran acetogenins, from the leaves of annona muricata in honour of professor G. H. Neil Towers 75th birthday," Phytochemistry, vol. 49, no. 2, pp. 565-571, 1998.

[48] M. J. Rieser, J. F. Kozlowski, K. V. Wood, and J. L. McLaughlin, "Muricatacin: a simple biologically active acetogenin derivative from the seeds of annona muricata (annonaceae)," Tetrahedron Letters, vol. 32, no. 9, pp. 1137-1140, 1991.

[49] M. Rieser, X. P. Fang, J. Rupprecht, Y. H. Hui, D. Smith, and J. McLaughlin, "Bioactive single-ring acetogenins from seed extracts of Annona muricata," Planta Medica, vol. 59, no. 1, pp. 91-92, 1993.

[50] M. J. Rieser, X. P. Fang, J. E. Anderson, L. R. Miesbauer, D. L. Smith, and J. L. McLaughlin, "Muricatetrocins-a and muricatetrocins- $\mathrm{B}$ and gigantetrocin- $\mathrm{B}-3$ new cytotoxic monotetrahydrofuran-ring acetogenins from Annonamuricata (Vol 76, Pg 2433, 1993)," Helvetica Chimica Acta, vol. 77, pp. 882-882, 1994.

[51] N. Badrie and A. G. Schauss, "Soursop (Annona muricata L.): composition, nutritional value, medicinal uses, and toxicology," in Bioactive Foods in Promoting Health, R. R. Watson and V. R. Preedy, Eds., Oxford, 2009.

[52] H. Baillon, Histoire des Plantes, Librairie de L. H Hachette, Paris, 1869.

[53] S. D. Karou, T. Tchacondo, M. A. Djikpo Tchibozo et al., "Ethnobotanical study of medicinal plants used in the management of diabetes mellitus and hypertension in the Central Region of Togo," Pharmaceutical Biology, vol. 49, no. 12, pp. 1286-1297, 2011.

[54] N. T. Florence, M. Z. Benoit, K. Jonas et al., "Antidiabetic and antioxidant effects of Annona muricata (Annonaceae), aqueous extract on streptozotocin-induced diabetic rats," Journal of Ethnopharmacology, vol. 151, no. 2, pp. 784790, 2014.

[55] J. L. Longuefosse and E. Nossin, "Medical ethnobotany survey in Martinique," Journal of Ethnopharmacology, vol. 53, no. 3, pp. 117-142, 1996.

[56] N. Liu, H. L. Yang, P. Wang et al., "Functional proteomic analysis revels that the ethanol extract of Annona muricata L. induces liver cancer cell apoptosis through endoplasmic reticulum stress pathway," Journal of Ethnopharmacology, vol. 189, pp. 210-217, 2016.

[57] C. Yang, S. R. Gundala, R. Mukkavilli, S. Vangala, M. D. Reid, and R. Aneja, "Synergistic interactions among flavonoids and acetogenins in Graviola (Annona muricata) leaves confer protection against prostate cancer," Carcinogenesis, vol. 36, no. 6, pp. 656-665, 2015.

[58] S. U. F. Syed Najmuddin, M. F. Romli, M. Hamid, N. B. Alitheen, and N. M. A. Nik Abd Rahman, "Anti-cancer effect of Annona muricata Linn leaves crude extract (AMCE) on breast cancer cell line," BMC Complementary and Alternative Medicine, vol. 16, no. 1, p. 311, 2016.

[59] K. Foster, N. Younger, W. Aiken, D. Brady-West, and R. Delgoda, "Reliance on medicinal plant therapy among cancer patients in Jamaica," Cancer Causes \& Control, vol. 28, no. 11, pp. 1349-1356, 2017.

[60] Y. N. Clement, V. Mahase, A. Jagroop et al., "Herbal remedies and functional foods used by cancer patients attending specialty oncology clinics in Trinidad," BMC Complementary and Alternative Medicine, vol. 16, no. 1, p. 399, 2016.

[61] K. Prabhakaran, G. Ramasamy, U. Doraisamy, J. Mannu, R. K., and J. Murugesan, "Polyketide natural products, acetogenins from graviola (Annona muricata L), its biochemical, cytotoxic activity and various analyses through computational and bio-programming methods," Current Pharmaceutical Design, vol. 22, no. 34, pp. 5204-5210, 2016.

[62] Z. Hajdu and J. Hohmann, "An ethnopharmacological survey of the traditional medicine utilized in the community of Porvenir, Bajo Paraguá Indian Reservation, Bolivia," Journal of Ethnopharmacology, vol. 139, no. 3, pp. 838857, 2012.

[63] R. A. Ritter, M. V. B. Monteiro, F. O. B. Monteiro et al., "Ethnoveterinary knowledge and practices at Colares island, Pará state, eastern Amazon, Brazil," Journal of Ethnopharmacology, vol. 144, no. 2, pp. 346-352, 2012.

[64] D. P. Sreekeesoon and M. F. Mahomoodally, "Ethnopharmacological analysis of medicinal plants and animals used in the treatment and management of pain in Mauritius," Journal of Ethnopharmacology, vol. 157, pp. 181-200, 2014.

[65] A. Asase, D. N. Hesse, and M. S. J. Simmonds, "Uses of multiple plants prescriptions for treatment of malaria by some communities in southern Ghana," Journal of Ethnopharmacology, vol. 144, no. 2, pp. 448-452, 2012.

[66] B. H. Mithun Pai, G. Rajesh, R. Shenoy, and A. Rao, "Antimicrobial efficacy of soursop leaf extract (Annona muricata) on oral pathogens: an in-vitro study," Journal of Clinical and Diagnostic Research, vol. 10, no. 11, pp. ZC01-ZC04, 2016.

[67] A. P. Oliveira, I. Sá, D. M. Pereira, R. F. Gonçalves, P. B. Andrade, and P. Valentão, "Exploratory studies on the in vitro anti-inflammatory potential of two herbal teas (Annona muricata L. and Jasminum grandiflorum L.), and 
relation with their phenolic composition," Chemistry \& Biodiversity, vol. 14, no. 6, article e1700002, 2017.

[68] F. F. Boyom, P. V. T. Fokou, L. R. T. Yamthe et al., "Potent antiplasmodial extracts from Cameroonian Annonaceae," Journal of Ethnopharmacology, vol. 134, no. 3, pp. 717-724, 2011.

[69] S. B. Santhosh, C. Ragavendran, and D. Natarajan, "Spectral and HRTEM analyses of Annona muricata leaf extract mediated silver nanoparticles and its Larvicidal efficacy against three mosquito vectors Anopheles stephensi, Culex quinquefasciatus, and Aedes aegypti," Journal of Photochemistry and Photobiology B: Biology, vol. 153, pp. 184-190, 2015.

[70] S. B. Santhosh, R. Yuvarajan, and D. Natarajan, "Annona muricata leaf extract-mediated silver nanoparticles synthesis and its larvicidal potential against dengue, malaria and filariasis vector," Parasitology Research, vol. 114, no. 8, pp. 3087-3096, 2015.

[71] J. Paul, R. Gnanam, R. Jayadeepa, and L. Arul, "Anti cancer activity on Graviola, an exciting medicinal plant extract vs various cancer cell lines and a detailed computational study on its potent anti-cancerous leads," Current Topics in Medicinal Chemistry, vol. 13, no. 14, pp. 1666-1673, 2013.

[72] D. J. Newman and G. M. Cragg, "Natural products as sources of new drugs from 1981 to 2014," Journal of Natural Products, vol. 79, no. 3, pp. 629-661, 2015.

[73] B. Schmidt, D. M. Ribnicky, A. Poulev, S. Logendra, W. T. Cefalu, and I. Raskin, "A natural history of botanical therapeutics," Metabolism, vol. 57, Supplement 1, pp. S3-S9, 2008.

[74] G. C. Winkler, E. L. Barle, G. Galati, and W. M. Kluwe, "Functional differentiation of cytotoxic cancer drugs and targeted cancer therapeutics," Regulatory Toxicology and Pharmacology, vol. 70, no. 1, pp. 46-53, 2014.

[75] R. I. Erickson, J. Tarrant, G. Cain et al., "Toxicity profile of small-molecule IAP antagonist GDC-0152 is linked to TNF- $\alpha$ pharmacology," Toxicological Sciences, vol. 131, no. 1, pp. 247-258, 2012.

[76] C. C. Liaw, J. R. Liou, T. Y. Wu et al.A. Kinghorn, H. Falk, S. Gibbons et al., "Acetogenins from Annonaceae," in Progress in the Chemistry of Organic Natural Products, vol. 101 of Progress in the Chemistry of Organic Natural Products 101, pp. 113-230, Springer, Cham, 2016.

[77] S. Z. Moghadamtousi, M. Fadaeinasab, S. Nikzad, G. Mohan, H. Ali, and H. Kadir, "Annona muricata (Annonaceae): a review of its traditional uses, isolated acetogenins and biological activities," International Journal of Molecular Sciences, vol. 16, no. 7, pp. 15625-15658, 2015.

[78] J. L. McLaughlin, "Paw paw and cancer: annonaceous acetogenins from discovery to commercial products," Journal of Natural Products, vol. 71, no. 7, pp. 1311-1321, 2008.

[79] G. Deep, R. Kumar, A. K. Jain et al., "Graviola inhibits hypoxia-induced NADPH oxidase activity in prostate cancer cells reducing their proliferation and clonogenicity," Scientific Reports, vol. 6, no. 1, article 23135, 2016.

[80] F. R. Chang, C. C. Liaw, C. Y. Lin, C. J. Chou, H. F. Chiu, and Y. C. Wu, "New adjacent Bis-tetrahydrofuran Annonaceous acetogenins from Annona muricata," Planta Medica, vol. 69, no. 3, pp. 241-246, 2003.

[81] C.-C. Liaw, F. R. Chang, C. Y. Lin et al., "New cytotoxic monotetrahydrofuran Annonaceous acetogenins from Annona muricata," Journal of Natural Products, vol. 65, no. 4, pp. 470-475, 2002.
[82] F. R. Chang and Y. C. Wu, "Novel cytotoxic annonaceous acetogenins from Annona muricata," Journal of Natural Products, vol. 64, no. 7, pp. 925-931, 2001.

[83] D. Cortes, S. H. Myint, A. Laurens, R. Hocquemiller, M. Leboeuf, and A. Cavé, "Corossolone et corossoline, deux nouvelles $\gamma$-lactones mono-tétrahydrofuraniques cytotoxiques," Canadian Journal of Chemistry, vol. 69, no. 1, pp. 811, 1991.

[84] M. J. Rieser, X.-P. Fang, J. E. Anderson, L. R. Miesbauer, D. L. Smith, and J. L. McLaughlin, "Muricatetrocins A and B and gigantetrocin B: three new cytotoxic monotetrahydrofuranring acetogenins from Annona muricata," Helvetica Chimica Acta, vol. 76, no. 7, pp. 2433-2444, 1993.

[85] M. J. Rieser, Z. M. Gu, X. P. Fang, L. Zeng, K. V. Wood, and J. L. McLaughlin, "Five novel mono-tetrahydrofuran ring acetogenins from the seeds of Annona muricata," Journal of Natural Products, vol. 59, no. 2, pp. 100-108, 1996.

[86] F. E. Wu, L. Zeng, Z. M. Gu et al., "New bioactive monotetrahydrofuran Annonaceous acetogenins, annomuricin $\mathrm{C}$ and muricatocin $\mathrm{C}$, from the leaves of Annona muricata," Journal of Natural Products, vol. 58, no. 6, pp. 909-915, 1995.

[87] M. Stimpfel and I. Virant-Klun, "Cancer incidence and mortality worldwide: sources, methods and major patterns in GLOBOCAN 2012," Journal of Cancer Stem Cell Research, vol. 4, no. 3, p. 1, 2016.

[88] S. Evangelista-Lozano, J. G. Cruz-Castillo, S. Pérez-González, E. Mercado-Silva, and G. Dávila-Ortiz, "Producción Y Calidad Frutícola De GuanábanOS (Annona muricata L.) Provenientes De Semilla De Jiutepec, Morelos, México," Revista Chapingo Serie Horticultura, vol. IX, no. 1, pp. 69-79, 2003.

[89] V. C. George, D. R. N. Kumar, V. Rajkumar, P. K. Suresh, and R. A. Kumar, "Quantitative assessment of the relative antineoplastic potential of the n-butanolic leaf extract of Annona muricata Linn. in normal and immortalized human cell lines," Asian Pacific Journal of Cancer Prevention, vol. 13, no. 2, pp. 699-704, 2012.

[90] A. Capes-Davis, G. Theodosopoulos, I. Atkin et al., "Check your cultures! A list of cross-contaminated or misidentified cell lines," International Journal of Cancer, vol. 127, no. 1, pp. 1-8, 2010

[91] V. P. Magadi, V. Ravi, A. Arpitha, Litha, K. Kumaraswamy, and K. Manjunath, "Evaluation of cytotoxicity of aqueous extract of Graviola leaves on squamous cell carcinoma cell25 cell lines by 3-(4,5-dimethylthiazol-2-Yl) -2,5-diphenyltetrazolium bromide assay and determination of percentage of cell inhibition at G2M phase of cell cy," Contemporary Clinical Dentistry, vol. 6, no. 4, pp. 529-533, 2015.

[92] M. Rosdi, N. Daud, R. Zulkifli, and H. Yaakob, "Cytotoxic effect of Annona muricata Linn leaves extract on Capan-1 cells," Journal of Applied Pharmaceutical Science, vol. 5, pp. 45-48, 2015.

[93] Y. Gavamukulya, F. Abou-Elella, F. Wamunyokoli, and H. AEl-Shemy, "Phytochemical screening, anti-oxidant activity and in vitro anticancer potential of ethanolic and water leaves extracts of Annona muricata (Graviola)," Asian Pacific Journal of Tropical Medicine, vol. 7, pp. S355-S363, 2014.

[94] L. Indrawati, P. Ascobat, B. Bela, M. Abdullah, and I. S. Surono, "The effect of an Annona muricata leaf extract on nutritional status and cytotoxicity in colorectal cancer: a 
randomized controlled trial," Asia Pacific Journal of Clinical Nutrition, vol. 26, no. 4, pp. 606-612, 2017.

[95] A. Quispe, D. Zavala, J. Rojas, M. Posso, and A. Vaisberg, "Efecto citotóxico selectivo in vitro de muricin $\mathrm{H}$ (acetogenina de Annona muricata) en cultivos celulares de cáncer de pulmón," Revista Peruana de Medicina Experimental y Salud Pública, vol. 23, pp. 265-269, 2006.

[96] V. Oviedo, M. García, C. Díaz et al., "Extracto y fracción alcaloidal de Annona muricata con actividad de tipo ansiolítica en ratones," Revista Colombiana de Ciencias Químico-Farmacéuticas, vol. 38, pp. 105-120, 2009.

[97] J. Brown, S. J. Reading, S. Jones et al., "Critical evaluation of ECV304 as a human endothelial cell model defined by genetic analysis and functional responses: a comparison with the human bladder cancer derived epithelial cell line T24/83," Laboratory Investigation, vol. 80, no. 1, pp. 3745, 2000.

[98] S. Yang, S. Mei, H. Jin et al., "Identification of two immortalized cell lines, ECV304 and bEnd3, for in vitro permeability studies of blood-brain barrier," PLoS One, vol. 12, no. 10, article e0187017, 2017.

[99] S. W. G. Tait and D. R. Green, "Mitochondria and cell death: outer membrane permeabilization and beyond," Nature Reviews Molecular Cell Biology, vol. 11, no. 9, pp. 621-632, 2010.

[100] P. Indovina, F. Pentimalli, N. Casini, I. Vocca, and A. Giordano, "RB1 dual role in proliferation and apoptosis: cell fate control and implications for cancer therapy," Oncotarget, vol. 6, no. 20, pp. 17873-17890, 2015.

[101] S. Goldar, M. S. Khaniani, S. M. Derakhshan, and B. Baradaran, "Molecular mechanisms of apoptosis and roles in cancer development and treatment," Asian Pacific Journal of Cancer Prevention, vol. 16, no. 6, pp. 2129-2144, 2015.

[102] R. C. Taylor, S. P. Cullen, and S. J. Martin, "Apoptosis: controlled demolition at the cellular level," Nature Reviews Molecular Cell Biology, vol. 9, no. 3, pp. 231-241, 2008.

[103] J. F. R. Kerr, A. H. Wyllie, and A. R. Currie, "Apoptosis: a basic biological phenomenon with wideranging implications in tissue kinetics," British Journal of Cancer, vol. 26, no. 4, pp. 239-257, 1972.

[104] M. L. Xu, J. Hu, B. P. Guo, Y. R. Niu, C. Xiao, and Y. X. Xu, "Exploration of intrinsic and extrinsic apoptotic pathways in zearalenone-treated rat sertoli cells," Environmental Toxicology, vol. 31, no. 12, pp. 1731-1739, 2016.

[105] A. Chalah and R. Khosravi-Far, "The mitochondrial death pathway," in Programmed Cell Death in Cancer Progression and Therapy, vol. 615 of Advances in Experimental Medicine and Biology, pp. 25-45, Springer, Dordrecht, 2008.

[106] C. Langlais, M. A. Hughes, K. Cain, and M. MacFarlane, "In vitro assembly and analysis of the apoptosome complex," Cold Spring Harbor Protocols, vol. 2015, no. 12, 2015.

[107] M. Brentnall, L. Rodriguez-Menocal, R. de Guevara, E. Cepero, and L. H. Boise, "Caspase-9, caspase-3 and caspase-7 have distinct roles during intrinsic apoptosis," BMC Cell Biology, vol. 14, no. 1, p. 32, 2013.

[108] D. Siegmund, D. Mauri, N. Peters et al., "Fas-associated death domain protein (FADD) and caspase- 8 mediate upregulation of c-Fos by Fas ligand and tumor necrosis factorrelated apoptosis-inducing ligand (TRAIL) via a FLICE inhibitory protein (FLIP)-regulated pathway," Journal of Biological Chemistry, vol. 276, no. 35, pp. 32585-32590, 2001.
[109] E. Kavanagh, "Quantification of active caspase-3 and active caspase-8 in microglia cells," Methods in Molecular Biology, vol. 1041, pp. 113-120, 2013.

[110] L. L. Pan, A. Y. Wang, Y. Q. Huang, Y. Luo, and M. Ling, "Mangiferin induces apoptosis by regulating Bcl-2 and Bax expression in the CNE2 nasopharyngeal carcinoma cell line," Asian Pacific Journal of Cancer Prevention, vol. 15, no. 17, pp. 7065-7068, 2014.

[111] W. Xu, L. Jing, Q. Wang et al., "Bax-PGAM5L-Drp1 complex is required for intrinsic apoptosis execution," Oncotarget, vol. 6, no. 30, pp. 30017-30034, 2015.

[112] M. Abdullah, A. F. Syam, S. Meilany et al., "The value of caspase-3 after the application of Annona muricata leaf extract in COLO-205 colorectal cancer cell line," Gastroenterology Research and Practice, vol. 2017, Article ID 4357165, 5 pages, 2017.

[113] J. Gomes de Melo, T. A. de Sousa Araújo, V. Thijan Nobre de Almeida e Castro et al., "Antiproliferative activity, antioxidant capacity and tannin content in plants of semi-arid northeastern Brazil," Molecules, vol. 15, no. 12, pp. 85348542, 2010.

[114] J. C. Chamcheu, I. Rady, R.-C. N. Chamcheu et al., "Graviola (Annona muricata) Exerts Anti-Proliferative, AntiClonogenic and Pro-Apoptotic Effects in Human NonMelanoma Skin Cancer UW-BCC1 and A431 Cells In Vitro: Involvement of Hedgehog Signaling," International Journal of Molecular Sciences, vol. 19, no. 6, p. 1791, 2018.

[115] J. Zhang, X. Lou, L. Jin et al., "Necrosis, and then stress induced necrosis-like cell death, but not apoptosis, should be the preferred cell death mode for chemotherapy: clearance of a few misconceptions," Oncoscience, vol. 1, pp. 407-422, 2014.

[116] T. Matsuoka and M. Yashiro, "Rho/ROCK signaling in motility and metastasis of gastric cancer," World Journal of Gastroenterology, vol. 20, no. 38, article 13756, 13766 pages, 2014.

[117] H. Zhou, B. Zhang, J. Zheng et al., "The inhibition of migration and invasion of cancer cells by graphene via the impairment of mitochondrial respiration," Biomaterials, vol. 35, no. 5, pp. 1597-1607, 2014.

[118] D. M. Hansra, O. Silva, A. Mehta, and E. Ahn, "Patient with metastatic breast cancer achieves stable disease for 5 years on graviola and xeloda after progressing on multiple lines of therapy," Breast Cancer Research, vol. 3, no. 3, pp. 84-87, 2014.

[119] O. V. de Sousa, G. D. V. Vieira, J. J. R. G. de Pinho, C. H. Yamamoto, and M. S. Alves, "Antinociceptive and antiinflammatory activities of the ethanol extract of Annona muricata L. leaves in animal models," International Journal of Molecular Sciences, vol. 11, no. 5, pp. 2067-2078, 2010.

[120] Y. Gavamukulya, F. Wamunyokoli, and H. A. el-Shemy, "Annona muricata: is the natural therapy to most disease conditions including cancer growing in our backyard? A systematic review of its research history and future prospects," Asian Pacific Journal of Tropical Medicine, vol. 10, no. 9, pp. 835-848, 2017.

[121] R. A. Hamid, C. P. Foong, Z. Ahmad, and M. K. Hussain, "Antinociceptive and anti-ulcerogenic activities of the ethanolic extract of Annona muricata leaf," Revista Brasileira de Farmacognosia, vol. 22, no. 3, pp. 630-641, 2012.

[122] I. O. Ishola, O. Awodele, A. M. Olusayero, and C. O. Ochieng, "Mechanisms of analgesic and anti-inflammatory properties of Annona muricata Linn. (Annonaceae) fruit extract in 
rodents," Journal of Medicinal Food, vol. 17, no. 12, pp. 13751382, 2014.

[123] D. R. Laksmitawati, A. P. Prasanti, N. Larasinta et al., “Antiinflammatory potential of gandarusa (Gendarussa vulgaris Nees) and soursoup (Annona muricata L) extracts in LPS stimulated-macrophage cell (RAW264.7)," Journal of Natural Remedies, vol. 16, no. 2, pp. 73-81, 2016.

[124] V. C. George, D. R. N. Kumar, P. K. Suresh, and R. A. Kumar, "Antioxidant, DNA protective efficacy and HPLC analysis of Annona muricata (soursop) extracts," Journal of Food Science and Technology, vol. 52, no. 4, pp. 23282335, 2015.

[125] Y. R. Son, E. H. Choi, G. T. Kim, T. S. Park, and S. M. Shim, "Bioefficacy of graviola leaf extracts in scavenging free radicals and upregulating antioxidant genes," Food \& Function, vol. 7, no. 2, pp. 861-871, 2016.

[126] P. Padma, J. P. Chansouria, and R. L. Khosa, "Hepatoprotective activity of Annona muricata Linn. and Polyalthia cerasoides bedd," Ancient Science of Life, vol. 19, no. 1-2, pp. 7-10, 1999.

[127] S. K. Sarin, "Alcohol for endoscopic sclerotherapy: there is truth in wine," Indian Journal of Gastroenterology, vol. 9, no. 1, pp. 84-87, 1990.

[128] S. M. Barbalho, M. S. Soares de Souza, P. C. S. Bueno et al., "Annona montana fruit and leaves improve the glycemic and lipid profiles of Wistar rats," Journal of Medicinal Food, vol. 15, no. 10, pp. 917-922, 2012.

[129] M. Leboeuf, C. Legueut, A. Cavé, J. Desconclois, P. Forgacs, and H. Jacquemin, "Alcaloïdes des Annonacées XXIX[1]: Alcaloïdes de l'Annona muricata L.," Planta Medica, vol. 42, no. 5, pp. 37-44, 1981.

[130] C. Bories, P. Loiseau, D. Cortes et al., "Antiparasitic activity of Annona muricata and Annona cherimolia seeds," Planta Medica, vol. 57, no. 5, pp. 434-436, 1991.

[131] E. Osorio, G. J. Arango, N. Jiménez et al., "Antiprotozoal and cytotoxic activities in vitro of Colombian Annonaceae," Journal of Ethnopharmacology, vol. 111, no. 3, pp. 630-635, 2007.

[132] N. S. Vila-Nova, S. M. de Morais, M. J. C. Falcão et al., "Different susceptibilities of Leishmania spp. promastigotes to the Annona muricata acetogenins annonacinone and corossolone, and the Platymiscium floribundum coumarin scoparone," Experimental Parasitology, vol. 133, no. 3, pp. 334-338, 2013.

[133] J. Mathew, R. George, R. Theruvil, T. C. Padavil, L. Tomy, and A. Kurian, "Antibacterial activity of leaf extract of Annona muricata and Simarouba glauca on Enterococcus faecalis," The Journal of Contemporary Dental Practice, vol. 17, no. 8, pp. 650-653, 2016.

[134] M. K. Simo, M. D. Nguepi, M. L. Sameza, R. K. Toghueo, F. B. Fekam, and G. Froldi, "Cameroonian medicinal plants belonging to Annonaceae family: radical scavenging and antifungal activities," Natural Product Research, pp. 1-4, 2017.

[135] M. R. Mohd Abd Razak, A. Afzan, R. Ali et al., "Effect of selected local medicinal plants on the asexual blood stage of chloroquine resistant Plasmodium falciparum," BMC Complementary and Alternative Medicine, vol. 14, no. 1, p. 492, 2014.

[136] L. R. T. Yamthe, P. Fokou, C. Mbouna et al., "Extracts from Annona Muricata L. and Annona Reticulata L. (Annonaceae) potently and selectively inhibit Plasmodium falciparum," Medicines, vol. 2, no. 2, pp. 55-66, 2015.
[137] M. Escobar-Khondiker, M. Hollerhage, M. P. Muriel et al., "Annonacin, a natural mitochondrial complex I inhibitor, causes tau pathology in cultured neurons," Journal of Neuroscience, vol. 27, no. 29, pp. 7827-7837, 2007.

[138] M. Höllerhage, T. W. Rösler, M. Berjas et al., "Neurotoxicity of dietary supplements from Annonaceae species," International Journal of Toxicology, vol. 34, no. 6, pp. 543-550, 2015.

[139] J. B. Minari and U. Okeke, "Chemopreventive effect of Annona muricata on DMBA-induced cell proliferation in the breast tissues of female albino mice," Egyptian Journal of Medical Human Genetics, vol. 15, no. 4, pp. 327-334, 2014.

[140] N. P. Okolie, K. Agu, and G. I. Eze, "Protective effect of ethanolic leaf extract of Annona muricata Linn on some early events in cycasinduced colorectal carcinogenesis in rats," Journal of Pharmaceutical and Scientific Innovation, vol. 2, no. 4, pp. 14-21, 2013.

[141] S. Hamizah, A. H. Roslida, O. Fezah, K. L. Tan, Y. S. Tor, and C. I. Tan, "Chemopreventive potential of Annona muricata L leaves on chemically-induced skin papillomagenesis in mice," Asian Pacific Journal of Cancer Prevention, vol. 13, no. 6, pp. 2533-2539, 2012. 


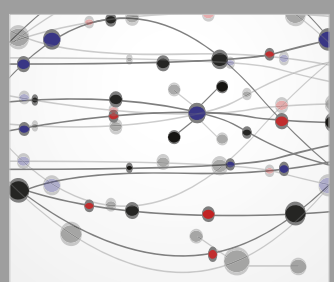

The Scientific World Journal
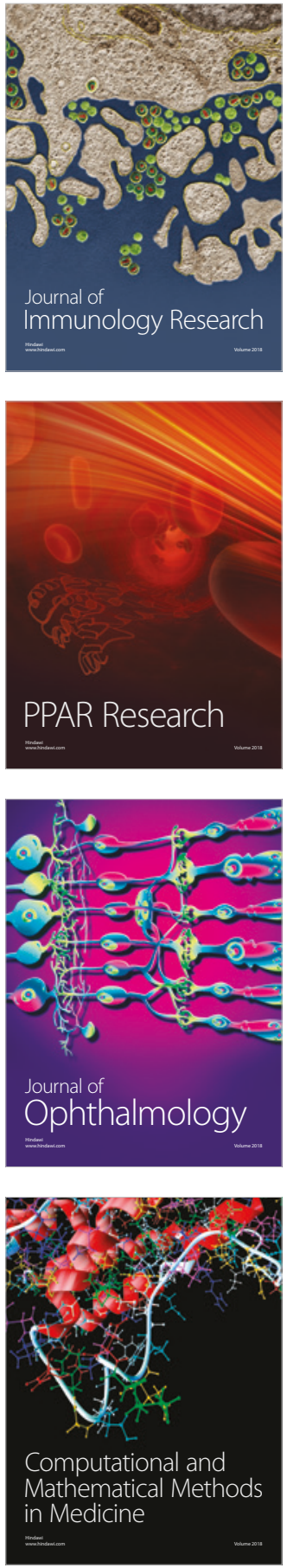

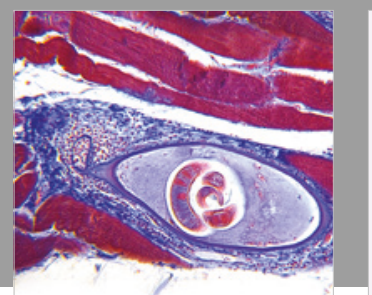

Gastroenterology Research and Practice

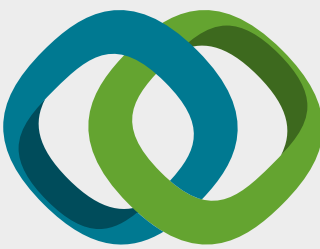

\section{Hindawi}

Submit your manuscripts at

www.hindawi.com
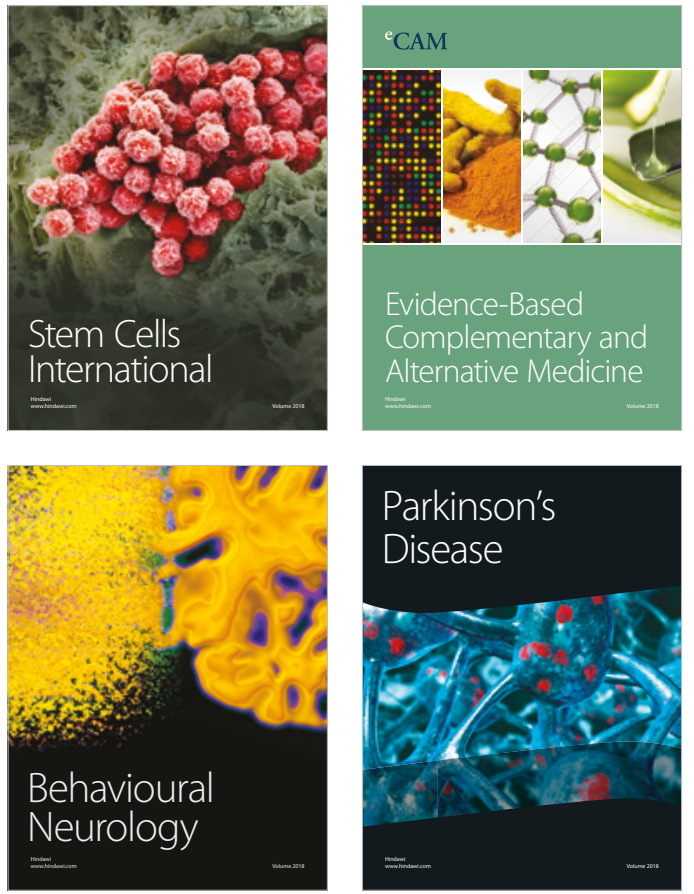

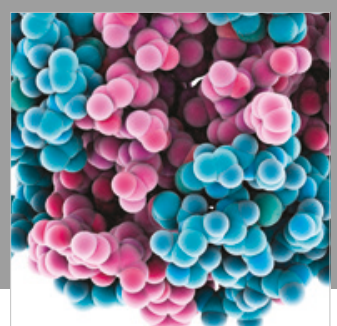

ournal of

Diabetes Research

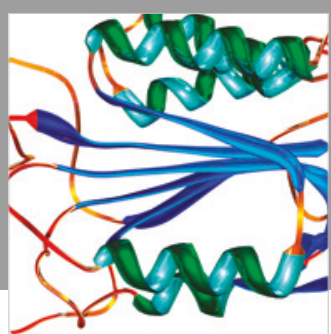

Disease Markers
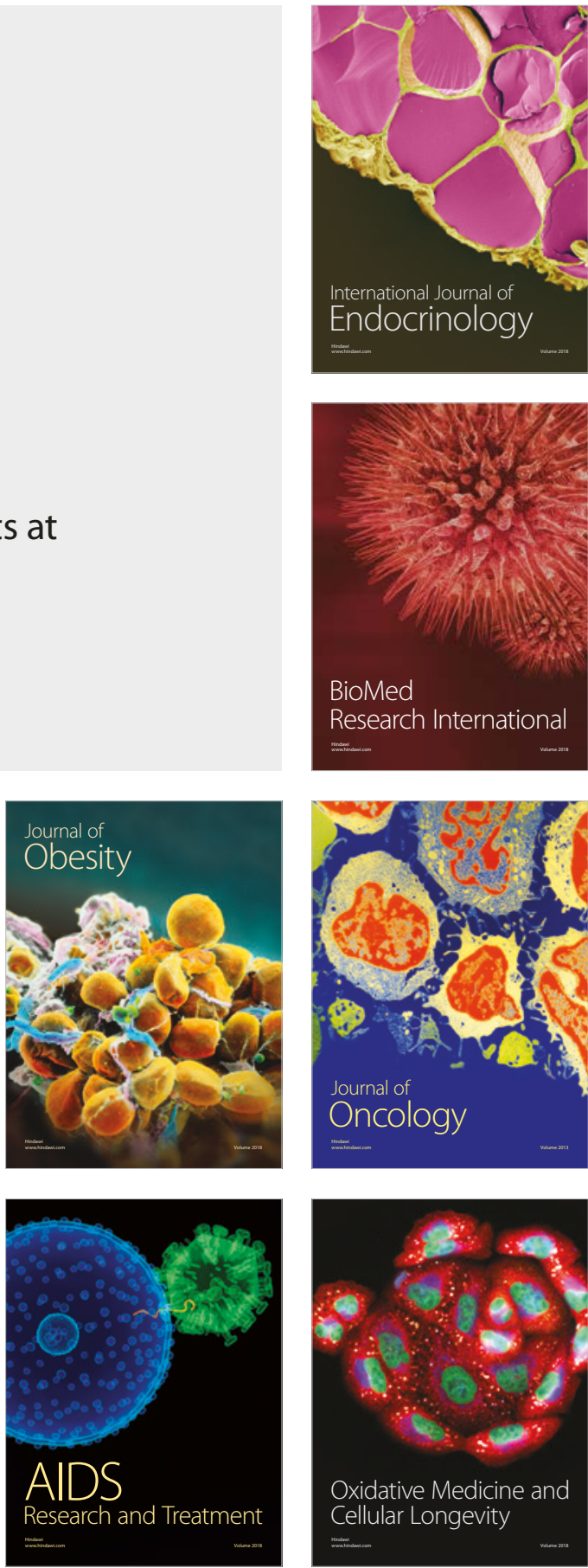